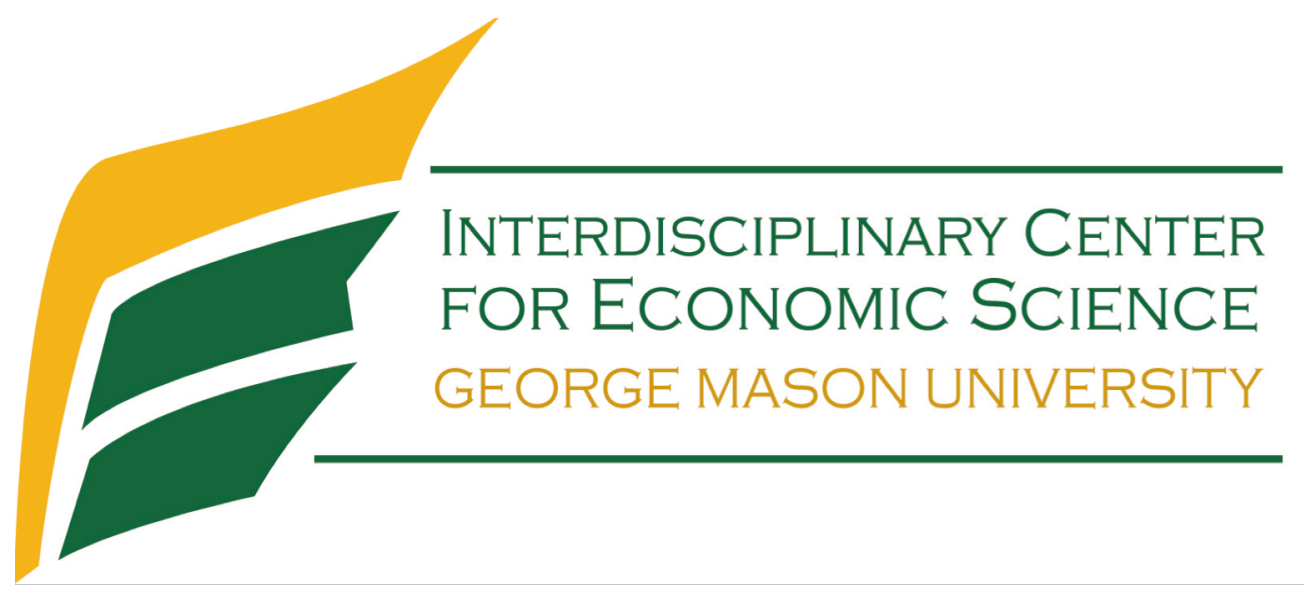

\title{
Richer (and Holier) than Thou? The Effect of Relative Income Improvements on Demand for Redistribution
}

\author{
Mounir Karadja, Johanna Mollerstrom, and David Seim
}

October 2014

Discussion Paper

Interdisciplinary Center for Economic Science

4400 University Drive, MSN 1B2, Fairfax, VA 22030

Tel: +1-703-993-4719 Fax: +1-703-993-4851

ICES Website: $h$ ttp://ices.gmu.edu

ICES RePEc Archive Online at: http://edirc.repec.org/data/icgmuus.html 


\title{
Richer (and Holier) than Thou? The Effect of Relative Income Improvements on Demand for Redistribution *
}

\author{
Mounir Karadja Johanna Mollerstrom $^{\ddagger} \quad$ David Seim ${ }^{\S}$ \\ October, 2014
}

\begin{abstract}
We study the extent to which people are misinformed about their relative position in the income distribution and the effects on preferences for redistribution of correcting faulty beliefs. We implement a tailor-made survey in Sweden and document that a vast majority of Swedes believe that they are poorer, relative to others, than they actually are. This is true across groups, but younger, poorer, less cognitively able and less educated individuals have perceptions that are further from reality. Using a second survey, we conduct an experiment by randomly informing a subsample about their true relative income position. Respondents who learn that they are richer than they thought demand less redistribution and increase their support for the Conservative Party. This result is entirely driven by prior right-of-center political preferences and not by altruism or moral values about redistribution. Moreover, the effect can be reconciled by people with political preferences to the right-of-center being more likely to view taxes as distortive and believe that it is personal effort rather than luck that is most influential for individual economic success.
\end{abstract}

*We are grateful to the Ragnar Söderberg Foundation, the Swedish Royal Academy of Sciences and the Lab for Economics Applications and Policy at Harvard for financial support. We thank Alberto Alesina, Raj Chetty, Olle Folke, Ilyana Kuziemko, Erzo Luttmer, Michael I. Norton, Ricardo Perez-Truglia, Stefanie Stantcheva and seminar participants at Harvard University and Columbia University for very helpful comments.

${ }^{\dagger}$ IIES, Stockholm University, Stockholm, Sweden.

${ }^{\ddagger}$ George Mason University, Fairfax, VA, USA, and the Research Institute of Industrial Economics, Stockholm, Sweden.

$\S$ University of Toronto, Toronto, Canada, Stockholm University and the Research Institute of Industrial Economics, Stockholm, Sweden. 


\section{Introduction}

Most governments redistribute economic resources between citizens and policies with redistributive components, such as social security and publicly financed health care, have increased greatly in importance over time (Alesina et al., 2004). The extent to which income and wealth are redistributed varies across countries, however, and the academic struggle to understand individual preferences for redistribution has been ongoing for decades. As many countries witness increasing inequality, questions about how people form and change their preferences for redistribution are likely to remain at the core of both the public and the academic debate.

Several theories have been suggested to explain how preferences for redistribution are formed. In seminal theoretical contributions, Romer (1975) and Meltzer and Richard (1981) suggest that a relatively richer person benefits less in monetary terms from redistribution and should therefore demand less of it. This prediction has found empirical support (see e.g. Alesina and Giuliano, 2010) but has also been scrutinized and challenged. For example, people often deviate from narrow monetary self-interest in that they also care about the consumption of others (Fehr and Schmidt, 1999; Bolton and Ockenfels, 2000), and such preferences tend to correlate with the demand for redistribution (Fong, 2001; Alesina and Giuliano, 2010). Beliefs about the income generating process have also been studied theoretically (Piketty, 1995; Benabou and Tirole, 2006) and beliefs about the extent to which individuals' economic success can be attributed to effort, rather than to luck, have been found to be a stronger determinant of preferences for redistribution than income itself (Fong, 2001).

These frameworks assume that agents are correctly informed about the income distribution. However, this assumption often proves to be false. Norton and Ariely (2011) document that Americans underestimate the current level of inequality and Kuziemko et al. (2013) show that Americans hold false beliefs about the link between taxes, economic growth, and inequality. In an Argentinian sample, Cruces et al. (2013) find that faulty beliefs about one's own relative position in the income distribution are common.

Given the documented presence of biased beliefs, it is natural to ask how individuals react to being provided with the correct information. Surprisingly, existing research has found small or no effects of such treatments. Cruces et al. (2013) show that respondents who believe that they are relatively richer than what they actually are demand more redistribution when provided with correct information. The effect is significant but the magnitude is small, and they find no effect of information provision on agents who underestimated their relative position. Similarly, Kuziemko et al. (2013) find that even though providing information about taxes and the distributions of income and wealth has a large impact on perceptions of whether inequality is an important problem, the effects on policy views and demand for redistribution are small.

The fact that information treatments, while ostensibly providing useful data, have had modest effects on political preferences may be the result of heterogeneous treatment effects across groups. For a given degree of misinformation, individuals might respond differently to receiving the correct information. This could, for example, be the case if there are interactions between the treatment and personal characteristics, beliefs or opinions. Taken together, this can give rise to a situation where some individuals respond strongly to treatment whereas others do not respond at all, thus yielding small effects on average. Depending 
on the direction of the treatment effects, this can also mean that information provision can increase the political polarization between groups (c.f. Lindqvist and Ostling, 2010)

In this paper, we report the result of a survey experiment which we conducted in order to investigate the presence of heterogeneities in misinformation about relative income, as well as in reactions to an information treatment. Our study was conducted in Sweden and we start by assessing the degree to which Swedes are misinformed about their position in the income distribution while also asking which people are particularly prone to holding erroneous beliefs. Thereafter, we study the impact of providing the correct information on respondents' demand for redistribution, party preferences and opinions on taxation, paying special attention to potential heterogeneities in the treatment effect.

The analysis is based on two tailor-made surveys. The first asked respondents to report beliefs about their perceived position in the Swedish income distribution. The data from the first survey are matched at the individual level to national administrative records containing information on age, income, wealth, education, civil status, government transfers and cognitive ability. We find that erroneous beliefs about own relative income are widespread: $74 \%$ of our respondents their relative position by more than 10 percentage points. Importantly, the vast majority of this group, $92 \%$, underestimate their position, i.e. believe that they are poorer relative to other Swedes than what they actually are. We show that the degree to which agents have false beliefs about their position varies, and document that people who are older, wealthier, more educated, and of higher cognitive ability have beliefs that are significantly closer to reality.

The second survey, which was sent to all respondents from the first survey, was conducted three months after the first and entailed a randomized experiment. At the beginning of the second survey, half of the respondents were provided with personalized information about their true relative position in the income distribution. Thereafter, we asked everyone, including those in the control group, about their demand for redistribution, party preferences and opinions on taxation. Methodologically, our paper is hence similar to other studies that use information as an experimental treatment in a field setting (Duflo and Saez, 2003; Card et al., 2012; Kuziemko et al., 2013; Cruces et al., 2013).

Our results show that giving people positive news about their relative income, i.e. informing them that they are relatively richer than they thought, increases the likelihood that they demand lower levels of redistribution and express support for the Conservative Party. Then, we examine if there are heterogeneities in the response to treatment and find that the average effect is entirely driven by the subset of respondents who expressed right-of-center political preferences in the first (pre-treatment) survey. While they respond to the positive relative income news by moving even further to the right on the political spectrum, both in terms of party preferences and in demanding less redistribution, people on the left are not at all impacted by the information treatment.

Several demographic characteristics, personal opinions and beliefs are correlated with right-of-center political preferences. We investigate mechanisms that could potentially underlie the heterogeneous treatment effect and show that this does not seem to arise because of economic or demographic differences between the right and the left (although such differences certainly exist). Furthermore, this is neither due to people on the right being less altruistic nor to them encompassing different moral values about the attractiveness of redistribution. Instead, we find that two beliefs about how the economy works can explain 
much of the heterogeneous response: whether effort rather than luck determines individuals' economic success and the degree to which income taxes distort labor supply.

It has been hypothesized that relatively low levels of redistribution in the United States may be due to misinformation about the income distribution, especially in light of recent increases in inequality (Kuziemko et al., 2013). Our setting sheds some light on the opposite situation: In Sweden, which has extensive redistribution and a high ratio of taxes to GDP compared to other countries, perceptions of relative income are clearly downward biased. This could, in turn, imply that misinformation about the income distribution contributes to Sweden's high levels of redistribution.

This study also relates to an extensive literature in economics and political science that studies the relationship between political preferences and personal economic conditions, such as income or wealth. ${ }^{1}$ Income has often been found to be correlated with political preferences, yet the causal relationship is not well understood. The question is made more difficult by the fact that there is likely to be a complex interaction with causality running in both directions and possibly self-reinforcing dynamics. Other underlying variables may also cause a correlation between income and political preferences. It may, for example, be that highability individuals who find it easy to succeed in life lean toward a more individualistic, rightwing world view and also have a well-paying job (see Mollerstrom and Seim, forthcoming, for evidence that high-IQ individuals favor less redistribution).

It is thus not surprising that the existing evidence on the impact of income on political preferences is mixed. Even though many studies provide evidence of self-interested political preferences and pocket-book voting (Peltzman, 1985; Durante et al., 2014; Elinder et al., 2010; Powdthavee and Oswald, 2014; Margalit, 2013), evidence for socially motivated political preferences has also been documented (see e.g., Sears and Funk, 1990). We contribute to this literature by experimentally (but truthfully) manipulating the perceptions of respondents' actual relative income, yielding identified estimates of causal effects with credible external validity. Moreover, we test for a causal impact on both the more well-defined, but abstract, measure of demand for redistribution and the broader, and arguably more politically relevant, question of party preferences.

Our results can also be interpreted as evidence of self-reinforcing relationships between beliefs, income and voting, which have previously been raised theoretically by Piketty (1995), Alesina and Angeletos (2005) and Benabou and Tirole (2006). They model agents whose initial beliefs about the economy affect their effort and income levels, which motivates their voting and, in turn, reinforces their pre-existing beliefs. Our finding of a sharp ideological divide in response to the same information (that a person is relatively richer, compared to others in society, than what he previously thought), which seems to be driven by differences in beliefs about the economy, is indicative of support for these models. The self-reinforcing nature of the relationship is further evidenced by another empirical result: right-of-center individuals hold a stronger belief in the role of effort in determining economic success pretreatment, and treatment strengthens this belief even further in this group.

The paper proceeds as follows. The next section describes our experiment and the result-

\footnotetext{
${ }^{1}$ The regressor of interest in our experiment is the (perceived) position in the income distribution rather than the income level per se. However, the key issues are analogous to our setting. Indeed, in terms of the canonical Meltzer and Richard (1981) model, relative income is the relevant parameter for (self-interested) voting, as opposed to absolute income.
} 
ing data which consists of answers to the two surveys and the linked administrative data. In Section 3, we document the results from the first survey and describe the bias in beliefs about the relative position in the income distribution held by the Swedes. Section 4 reports on the second survey and the outcome of the experiment. Robustness considerations are discussed in Section 5 and Section 6 concludes.

\section{Data}

The surveys used in this study were designed by us and implemented in two waves by Statistics Sweden. This agency collects and handles official statistical data in Sweden. Conducting the study in collaboration with Statistics Sweden allowed us to link survey data with administrative records.

\subsection{The First Survey and Administrative Data}

The first survey was sent by postal mail to a representative sample of 4,500 Swedish citizens above 18 years of age in May 2011. Respondents were asked to report their annual income from the previous year (2010) and to state their perceived position in the national income distribution by answering the following question: "How many percent of the Swedish population (18 years or older) do you think have a total yearly income which is lower than yours?." Total yearly income was explicitly defined as the sum of labor and capital income before taxes, including pensions but exclusive of transfers such as unemployment insurance. In addition, respondents were asked to state what they believed the mean annual income in Sweden to be in 2010.

The first survey also asked respondents to report how often they use various information sources (the alternatives being $0=$ never, $1=$ every month, $2=$ every week and $3=$ every day), with the alternatives being printed newspapers, news on radio/TV, magazines, other radio/TV programs and news online. We define the variable Informed as the sum of the answers to each media, and a higher value of this variable thus indicates a more extensive media usage.

In addition, the first survey elicited political preferences, altruism, opinions on helping the poor through publicly administered redistribution, and beliefs about how distortive income taxation is and how individual economic success come about.

There are nine main political parties in Sweden. Preferences were elicited by asking respondents to state the party that they would vote for if there were to be an election at the point in time when the respondent filled out the survey. ${ }^{2}$ We use this to define an indicator of left-right preferences. The binary variable Right takes the value of 1 if the respondent stated an intention to vote for one of the four Swedish right-of-center parties and 0 otherwise. ${ }^{3}$

\footnotetext{
${ }^{2}$ The respondents also had the option to state that they did not know or did not want to answer, that they would cast a blank vote or that they would abstain from voting.

${ }^{3}$ In the appendix, we show that our specifications are robust to alternative definitions, including one where those who abstain from voting, cast blank votes, decline to answer or vote for non-traditional parties etc. are excluded from the analysis. Details about the left-right scale in Swedish politics can be found in Petersson (1994) and in Pettersson-Lidbom (2008). See also Alesina et al. (1997) for a comparison of the Swedish left-right scale with the American context. The parties included in Right is Moderata Samlingspar-
} 
A measure of altruism was elicited by asking respondents to indicate their willingness to donate to charitable causes on a 1-10 scale, where 10 indicated the highest willingness to donate. We define the binary variable Altruism to take the value of 1 if a respondent chose 6 or higher.

Moral values about assistance to the poor through redistribution were captured by the extent to which respondents agreed or disagreed on a 1-10 scale where 10 indicates complete agreement with the following two questions: (1) Redistribution is important because I believe that it leads to a more just society and (2) Redistribution is important because I care about others' standard of living. We give the binary variables Just and Care the value of 1 for responses above or equal to 6 to question (1) and (2), respectively, and we use these two variables to form the summary index Redist-Moral. Following Kling et al. (2007), the index is constructed by computing the equally weighted average of the Z-scores variables. A higher value of this index denotes a stronger support for these moral aspects of economic redistribution. ${ }^{4}$

We capture respondents' beliefs about the distortive effects of redistribution by the following statement: "Changes in income taxes influence how much people choose to work." The binary variable No Distort takes the value of 1 for respondents who reported an agreement to the statement of 5 or lower on a 1-10 scale (where 10 indicated complete agreement with the statement). The following question was used to elicit beliefs about how individual economic success comes about: "Is it mostly effort or luck that matters for how well an individual does economically in life?." Respondents indicated their answer on a 1-10 scale where 1 was defined as "Only luck" and 10 as "Only effort" and we define the binary indicator Luck for answers below or equal to 5 . If economic success is realized through effort, redistribution can be argued to be more distortive (Fong, 2001) and we use these two questions to form the index Redist-Distort using the same method as above. A lower value of this index indicates a stronger belief that redistribution creates inefficiencies and distortions.

A total of 1,562 people responded to the first survey. This corresponds to a response rate of 36 percent, which is common for postal mail surveys of a similar length carried out by Statistics Sweden.

To implement the randomized experiment in the second survey, answers to the questions about annual income and perceived relative income were needed. Thus, we exclude respondents with missing values to either of these questions. We also exclude respondents who stated that they are located above what they believe to be mean income but, at the same time, reported as being below the median income, as well as respondents where the difference between self-reported and administrative annual income for 2010 is so large that the respondent probably did not correctly understand the question. ${ }^{5}$ After these exclusions,

tiet, Folkpartiet, Centerpartiet and Kristdemokraterna. The remaining parties are Socialdemokraterna, Vänsterpartiet, Miljöpartiet, Feministiskt Initiativ and Sverigedemokraterna. In Section 5 we discuss robustness checks performed related to this definition.

${ }^{4}$ The Z-score is standardly computed by first subtracting the control group mean from each observation and then dividing by the control group standard deviation. Any missing values of the variables in the index are ignored when taking the mean to form the index.

${ }^{5}$ The results reported here are robust to ignoring the last two exclusion criteria. They are also robust to wide variations in the allowed divergence between stated and administratively reported income. In the specifications reported here, the cutoff was set at a difference between stated and administratively reported income of 750 percent. 
our sample consists of 1,242 respondents.

The survey responses were linked to national administrative records at the individual level. The main data set was the longitudinal integration database for health insurance and labor market studies (LISA, by Swedish acronym). LISA comprises information on age, education, civil status, number of children, home region, and government transfers such as unemployment insurance and social security benefits. In addition, the data were complemented with annual taxable income for the years 1999-2010, and with data on real estate and financial wealth for the year 2006 from the Income and Tax register. ${ }^{6}$

Finally, for a subset of men born after 1950 and before 1981, we retrieve test scores for cognitive ability from the Swedish Military Records. ${ }^{7}$ Until 1999, military enlistment was mandatory for all Swedish men. The enlistment normally took place in the year a man turned 18 or 19 and encompassed a test of cognitive ability. This test consisted of four subtests (logical ability, verbal ability, technological comprehension and metal folding), with 40 questions each, and is an accepted measure of intelligence (Carlstedt, 2000; Heckman et al., 2006; Lindqvist and Westman, 2012). We sum the subscores and percentile rank the sum within each enlistment year. Under the assumption that skills are normally distributed, we obtain a standardized variable by applying the inverse of the normal CDF to the percentile score.

Table 1 shows summary statistics for key variables for survey respondents (second column) and for the full Swedish population in the same age-range (first column). We note that those who responded are older, have fewer children at home, are more educated and have a higher income than non-respondents. ${ }^{8}$ Demographic variables are available for both the full population and for the sample from the first survey, making it possible to weight the sample to enhance the generalizability of the results to the population - see Section 5.

\subsection{Design of the Experiment and Second Survey}

In August 2011, three months after the first survey, another survey was sent to those who responded to the first survey. Half of the second round recipients were randomly selected to receive a treatment revealing their actual position in the income distribution.

The income distribution of the full Swedish population was calculated using administrative data. However, we used the self-reported income from the first survey to locate each individual's percentile, to avoid the variation that would stem from informing some subjects about both their absolute and their relative income. This procedure also makes our results comparable to previous studies, such as Cruces et al. (2013), which do not have access to administrative records.

Naturally, administrative and self-reported income are highly correlated. In Figure 1, we rank the sample according to income (measured in administrative data) and divide the observations into twenty equally-sized groups and show the mean stated income against the

\footnotetext{
${ }^{6}$ The reason that we have wealth data from 2006 is that the wealth tax was thereafter abolished and the data were no longer collected.

${ }^{7}$ There are men in our sample born before 1951, but for these cohorts, military enlistment data are not available in digitized form.

${ }^{8}$ According to Statistics Sweden, this is a typical pattern for the surveys in which they engage. The only divergence from their usual results is that we do not have significantly more women participating.
} 
mean administrative income in each group. The slope of 0.75 is flatter than the 45 -degree line, mainly because some people with very high incomes underreport, and some with very low earnings overreport.

The information about the respondent's position in the income distribution was provided using a figure (see Figure 2). This consisted of a horizontal line with numbers representing income deciles. For each decile, the actual median yearly income in 2010 was stated. A marker indicated where in the distribution the respondent's income was located. The following information was provided: In the previous survey, you reported an annual income for 2010 of $[X]$ SEK. In the figure below we have indicated where your income is located on the income scale. To ensure that respondents considered the information, this statement was immediately followed by a question asking individuals to categorize themselves as being in either one of the five lowest or one of the five highest deciles.

Note that the treatment is subtle as we do not explicitly compare an individual's actual position on the income scale with the beliefs stated in the first survey. This, together with the time lag between the two surveys, reduces the likelihood that our results are due to the framing effect that could arise if subjects were told that they were "right" or "wrong" in the first survey. After the information treatment and the follow-up question, the second survey was identical for both groups.

We use three outcome variables to study the effect of treatment on political preferences. The first is a question about demand for redistribution conducted by the government, where subjects indicate the preferred level of income redistribution. The scale was presented to subjects with 10 steps, with 1 being defined as no redistribution (meaning that the public sector does not influence the income distribution at all) and 10 as full redistribution (everyone receives the same income after taxes and subsidies). We define the variable Against-Redist as the indicator of providing an answer below 5 to this question (this corresponds to demanding redistribution below the control-group median).

Our second outcome variable, labeled Cons. Party, takes the value of 1 if the respondent reported that he would vote for the Conservative Party (Moderata Samlingspartiet in Swedish). This party is the one most strongly associated with preferences for low levels of taxation and redistribution among the Swedish parties. ${ }^{9}$

The third outcome variable is the response to the following question: Would you like to change the income taxes that we have in Sweden today, and if so in what way? Subjects who prefer to decrease taxes were assigned 1 for this indicator, labeled Decrease Tax (people who wanted no change or an increase were given the value of 0 ). We consider these three outcomes separately but we also create a summary index, as in Kling et al. (2007). A higher value of the Outcome Index represents political preferences more to the right on the political spectrum.

The response rate of the second survey was significantly higher than the first. This is not surprising as the first round selects individuals willing to fill out surveys in general. Of the first-round sample of 1,242, 80.5 percent, or 1001 people, completed the second round. Column (3) of Table 1 compares this sample to the Swedish population, and Table 2 investigates factors correlated with responding to the second survey, conditional on responding to the first. As in the first survey, older, highly educated people as well as high-income earners,

\footnotetext{
${ }^{9}$ cf. Petersson (1994) and Pettersson-Lidbom (2008).
} 
were more likely to respond to the second survey. Importantly, the random allocation to the treatment or control group did not have an impact on the likelihood that a person responded. The potential concern that individuals may perceive the information treatment to be intruding and hence abstain from responding is thus alleviated, as shown by the variable Treatment in Table 2.

Finally, Table 3 reports the results from the regression: treatment $_{i}=\alpha+\beta$ covariate $_{i}+\varepsilon_{i}$ within the sample that responded to the second survey. Reassuringly, treatment can be predicted by only one of 21 covariates: college education is less common in the treatment group (the coefficient is marginally statistically significant, $p<0.1$ ). Since the treatment and control groups were balanced with respect to this variable before sending out the second survey, we conduct our analysis both with and without controlling for college education as further discussed in Section 5. In the final sample, 49.5 percent (not significantly different from 50 percent) were in the treatment group.

\section{Bias in Perceptions of Relative Income}

To what extent do respondents have a biased perception of where in the income distribution they are located? We define the bias of a respondent as the difference between his actual and perceived income percentile. Respondents who underestimate (overestimate) their relative income by more than 10 percentage points are categorized as having a negative (positive) bias. The remaining subjects are defined as having no bias. ${ }^{10}$

Figure 3 displays the distribution of bias in our sample. It is substantially skewed to the right, indicating that a majority of respondents underestimate their position, i.e. believe that they are poorer, relative to other Swedes, than they actually are. ${ }^{11}$ In fact, $68 \%$ underestimate their relative income, while 6 percent overestimate it. That implies that out of those with an absolute bias of more than 10 percentage points, $92 \%$ have a negative bias. ${ }^{12}$

Weighting the observations by population weights, we find that $63 \%$ underestimate and $8 \%$ overestimate their relative income. This indicates that our result is not simply an effect of the characteristics of the people who chose to respond to our survey, but that Swedes in general believe that they are relatively poorer than they actually are. This finding differs from results found in previous studies from other countries with, for instance, Cruces et al. (2013) establishing that mis-perceptions about relative income are balanced in a sample of Argentinian citizens. For a comparison with US data, one can look to the General Social Survey. In the latest wave, 54 percent of the people in the bottom income quartile say that they believe themselves to have average or above average income, indicating that there is a substantial overestimation of relative income in the US.

\footnotetext{
${ }^{10}$ All results reported here are robust to varying the definition of bias by using a cutoff of 5 or 15 percentage points instead of 10 . The results are available upon request.

${ }^{11}$ While the median respondent underestimates her relative income with 18 percentiles (corresponding to about 130,000 SEK on average), the median error in reporting the level of income is only 3,300 SEK, indicating that respondents are not underestimating their relative income on purpose and that they are in fact uninformed about the income distribution.

${ }^{12}$ Defining bias groups using a cutoff of 5 percentage points from their true percentile instead of 10 , the distribution is similar: 77 percent underestimate, 9 percent overestimate and 14 percent have no bias.
} 
We next investigate if the bias differs across the income distribution. Figure 4 shows the perceived position in the income distribution in relation to the actual position. The estimated slope is 0.653 and significantly different from 1, which is the no-bias slope. Figure 5 shows the bias for subgroups. The first three panels divide the sample by whether or not a respondent has college education (panel A), had a cognitive ability at age 18 above the mean (panel B) and reports a usage of more media than average (panel C).

Respondents with at least college education have an estimated coefficient in the relation between perceived and actual relative income that is 0.081 units steeper than those without tertiary education. As the slopes are below 1, this implies that higher education reduces the bias. The same finding arises when comparing respondents with a cognitive ability above the mean to those with lower cognitive ability (note that this sample is smaller and comprised of men only). The difference in slope between the two groups is 0.17. People who use more media are slightly closer to the no-bias slope, but this difference is only marginally statistically significant.

We continue to divide the sample by whether or not a respondent lives in an urban area $^{13}$ (panel D), has right-of-center political preferences (panel E), or has wealth above the median (panel F). Living in an urban area can be argued to increase the exposure to individuals from different socio-economic groups and thereby improve the awareness of one's place in the income distribution. However, we find no support for this in the data as there is no difference in slope between the urban and non-urban groups. The same is true when comparing right-of-center individuals with non-right-of-center individuals.

However, we note that wealthier individuals are better at estimating their position in the income distribution. The same is true for men (panel $\mathrm{G}$ ), older individuals (panel $\mathrm{H}$ ) and those who are married (panel I), but note that the last result is only marginally statistically significant.

Relating these results to the canonical theoretical frameworks by Romer (1975) and Meltzer and Richard (1981), we see that the assumption of people having full and correct information about relative income does not hold. Moreover, the bias is not the same across groups. This might, in turn, contribute to polarizing groups further in their demand for redistribution as the bias is larger among those who generally want more redistribution (those with lower education, lower cognitive ability and singles; see Alesina and Giuliano, 2010; Mollerstrom and Seim, forthcoming), thus pushing their views even further away from those who generally want less redistribution.

\section{Correcting the bias}

We now investigate the impact of correcting faulty beliefs about relative income. Table 4 presents the average effects of treatment on the three outcome variables as well as on the composite Outcome index. Treatment leads to a significant shift in preferences to the right among those with a negative bias, i.e. among those who learn that they are relatively richer than they previously believed. Figure 6 visualizes the effect among respondents with a negative bias by plotting the distributions of the outcome variables for the treatment

\footnotetext{
${ }^{13}$ Defined as living in one of the four largest urban areas in Sweden: the Stockholm, Gothenburg, Malmö or Uppsala regions.
} 
and control groups. Panel A shows a shift in preferences for redistribution, with treated respondents having more weight on the lower end of the scale, i.e. wanting less redistribution. Panel B and C show similar patterns for support for the Conservative Party and willingness to change taxes, respectively. As shown in Column 2 of Table 4, treatment increases the probability of demanding redistribution below the median by 7.8 percentage points from a base of 40.3 percent in the control group, i.e. a $19.3 \%$ increase. It also increases support for the Conservative Party (Column 3) by 8.1 percentage points, a relative increase of $32.4 \%$ from the control group mean. Finally, in Column 4, the point estimate for willingness to decrease taxes is positive, but not significantly different from zero.

As an overwhelming majority of our respondents underestimated their relative income, we continue to focus on them and explore heterogeneities in how people respond to treatment. We first investigate the interaction of treatment and the support for a right-of-center party in the first survey, among those who underestimate their position. Figure 7 summarizes our results graphically and shows a pronounced difference in the response to treatment based on political preferences. Panels A, C and E show that the distribution of political preferences among the non-right is essentially identical across treatment and control groups. In contrast, panels $\mathrm{B}, \mathrm{D}$ and $\mathrm{F}$ show that the treatment group within the right exhibit even more right-oriented preferences as compared to the control group. Table 5 shows that within the right-of-center group, the treatment effect on the Outcome Index more than doubles in size as compared to the average effect while the effect among the non-right is a precisely estimated zero. The average treatment effects reported in Table 4 seem to be entirely driven by the respondents with prior right-of-center political preferences.

Columns 2 to 4 of Table 5 consider the outcome variables separately. The probability of demanding low levels of redistribution increases with treatment by approximately 13 percentage points among those with right-of-center party preferences. The support for the Conservative Party increases by approximately 15 percentage points, implying a re-shuffling of party allegiances within this group. In both cases, the treatment effect in the rest of the sample is close to zero and insignificant. For none of the groups, the willingness to decrease taxes is significantly affected. Finally, column 5 shows that those with prior right-of-center political preferences are both more likely to believe in the role of effort in determining economic success and that they increase this belief after receiving a relative income improvement, yielding support for theories of a self-reinforcing relationship between beliefs and ideology (Piketty, 1995; Alesina and Angeletos, 2005; Benabou and Tirole, 2006).

We next turn to investigating the mechanisms underlying the heterogeneous treatment effect. Table 6 shows that an individual's position on the left-right political spectrum is correlated with her age, education, cognitive ability, income and wealth. As these variables also predict having more correct beliefs about relative income, we investigate interactions between these factors and treatment. However, as shown in Table 7, the treatment effect is not impacted by any of these economic and demographic factors and hence does not provide an explanation for the stronger treatment effect among those to the right of center. In the appendix, Table A.1 shows that the heterogeneous effect for the right of center remains even when simultaneously testing for the heterogeneous effects of these variables.

Turning to beliefs about how the economy functions and how economic success is generated, Table 6 reveals that people with right-of-center preferences tend to believe that individual economic outcomes are the result of personal effort rather than luck. They are 
also more prone to think that income taxes create distortions by impacting labor supply. Table 8 reports the results of estimating separate treatment effects by prior beliefs. Column 1 shows that treated subjects on average support less redistributive policies, but that this effect is null for those who believe that redistribution is not distortive and that luck is the determinant of economic success. The same pattern emerges when looking at the outcome variables separately in columns $2-4$.

These results suggest that beliefs about how the economy works play an important role in shaping the response to the treatment. However, as these beliefs are correlated with rightof-center political preferences, the variation in columns 1-3 in Table 8 may be a result of this correlation. In column 4, we add a control variable for right-of-center political preferences and show that the treatment effect remains significant. Restricting the sample to the respondents who reported right-of-center preferences (column 5), the effect of the interaction with beliefs disappears. Finally, we restrict the sample to those who reported non-right preferences in the first survey (column 6) and even within this group, those who believe that taxation is distortive and that effort is more important than luck respond more to treatment (although the result is only marginally statistically significant for this group).

Table 6 shows that holding political preferences to the right of the center is correlated with less support both for the view that redistribution is a way of creating a just society and that redistribution is motivated because one cares about other people's consumption. However, Table 9 shows that none of the interactions between these variables and treatment are significant, suggesting that they are not driving the heterogeneous treatment effect. In this table, we also examine whether altruism explains the heterogeneous treatment effect, but find that it does not.

Finally, we report the results on the interaction between intensity of bias and treatment effect. We divide respondents who underestimate their relative income into three equally sized groups, labeled Low, Medium and High Bias. As can be seen in Table 10, we lack the power to disentangle any effects between these groups. Nevertheless, the Medium Bias group consistently responds more strongly to the treatment than the Low Bias group. For the High Bias group, this holds for Conservative Party support and the willingness to decrease taxes but not for demand for redistribution or the Outcome Index. These results should, however, be interpreted with caution. Because of our information treatment design, respondents are not explicitly told whether they have any bias or reminded of their previously stated belief, and are hence not told the size of their bias. Respondents will have to recall what they stated in the first survey, three months prior, and conclude if the information is positive or negative news. Therefore, it is likely that most respondents do not experience any clear differences in the intensity of treatment.

Taken together, we conclude that informing a person that he is relatively richer than he initially thought has very different effects depending on the political preferences. Those with right-of-center political preferences drive the treatment effect, and the underlying mechanism seems to be that they are more likely to believe that redistribution is distorting. 


\section{Robustness}

All robustness tests, including more detailed information about the tests, are available in the Appendix.

Tables A.2 and A.3 display our main specifications using two different cutoffs for defining a negative bias. Instead of defining those who underestimate their relative income by more than 10 percentage points as having a negative bias, Table A.2 uses a cutoff at 5 percentage points, while Table A.3 uses a cutoff at 15 percentage points. Both the average effects and the heterogeneous effects for those on the right are significant and similar in magnitude to using the 10 percentage point cutoff.

The recipients of the first survey were chosen as a representative sample of the Swedish population. However, as the response rate varies across subgroups of the population, our final sample is not representative. In Table A.4, we therefore run our main specifications using a weighted OLS regression applying population weights. Reassuringly, the results are similar both in magnitude and statistical significance.

We define four of the Swedish parties as right-of-center, following the previous literature. However, the political landscape is constantly changing, and the recently successful, populist, anti-immigration party "Sverigedemokraterna" (the Sweden Democrats) could also be argued to be a right-of-center party. We redo the relevant analysis in Table A.5, classifying support for this party as support for a center-of-right party and document that the results do not change. We also show that the analysis can be done using only the traditionally right-wing and left-wing parties without changing the results. This indicates that the categorization of people who answered that they would cast a blank vote, not vote at all, or vote for a non-traditional party is not important for the results.

Due to a lower response rate for party preferences in the second round of the survey, there is a smaller number of observations in column 2 than in the other columns of Table 4 . To investigate a possible attrition bias, we report results from two variations of the basic models in the appendix. In Table A.6, we first use the same specifications as in Table 4 but restrict the sample to the subset with non-missing values for party preference. These models exhibit the same pattern, but with somewhat stronger overall effects. To avoid basing our results only on those confident enough to indicate party preference in the second survey, we also show results under the assumption that those who did not respond would have cast blank votes (i.e. missing values are recoded to zeros). The effect is now stronger in magnitude and more precise, indicating that attrition may, if anything, attenuate our results towards zero.

We use the follow-up question that was asked immediately after the information provision in the treatment to test the possibility that those on the left-hand side of the political spectrum do not understand or acknowledge the information given in the treatment. In column 1 of Table A.7, we find that there is no significant difference across the left and right in correctly answering the follow-up question and identifying oneself as being placed in one of the five lowest or one of the five highest deciles.

It is possible that the treatment does not only provide an information shock, but also temporarily increases the salience of relative income. For those receiving information that they are above the median, the increased salience of relative income may increase the likelihood of reporting more right-leaning views, notwithstanding if the treatment provided any new information. If so, our results would not be entirely due to the information given in the 
treatment and one concern would be that the results could be transitory and diminish as the salience of relative income declines.

We first note that this explanation implies that our estimates would simultaneously be biased in two different directions since the treatment groups consist both of people who are informed that they are relatively poor (i.e. below the median) and those who are informed that they are relatively rich (i.e. above the median). This is tested in column 2 of Table A.7. We find no significant differences in the responses of the two subgroups for the sample of those who underestimated their relative income. This explanation also implies that participants who have no bias should respond to treatment despite not receiving any new information. In column 3 of Table A.7, we find no significant such effects, indicating that the effects we find are, in fact, due to the new information provided in the treatment.

In Table 3, we document that college education is significantly lower in the treatment group as compared to the control group. We redo the analysis using a number of control variables, including an indicator for whether a respondent has college education or not. The results are reported in the appendix, Tables A.8 to A.18, and we find that the inclusion of control variables does not change any of the conclusions reported here.

\section{Conclusion}

There are compelling reasons to believe that people's perceptions of their place in the income distribution are often incomplete or faulty. It has even been suggested that such misinformation underlies the relatively low levels of redistribution in the United States, where it is common that people overestimate their relative position and hence, believe that they are richer, relative to others, than what is actually the case.

We conduct a randomized survey experiment in Sweden and start by documenting that faulty beliefs are also common in Sweden. However, the direction is another: in our sample, almost 70 percent underestimate their relative position by more than 10 percentage points, i.e. believe that they are poorer relative to others. Only 6 percent overestimate their relative position by the same amount.

In order to provide a clearer picture of this pattern, we link the survey data to administrative records at the individual level. In general, people who are older, more educated, have a higher cognitive ability, and are wealthier have perceptions that are closer to reality. Even though these respondents still underestimate their relative income on average, they do so to a lesser extent.

We investigate whether faulty beliefs are actually of importance for policy preferences using a second survey, where we randomly select half of the respondents from the first survey and provide personalized information about own relative income. This information was sent three months after the first survey, thereby alleviating any concerns that the results are merely framing effects rather than true responses to the given information.

We find that people who believe that they are poorer than they actually are respond to the information treatment by changing their political preferences toward the right. Interestingly, this effect is entirely driven by individuals who indicated right-of-center political preferences

prior to treatment. In this group, the information about the true relative position leads to an increase in the support for the Conservative Party (i.e. to a re-shuffling of the allegiances 
with the right-of-center parties) and to a lower demand for redistribution. Instead of the information on relative earnings leading to more agreement among individuals regarding the desired policy, our results hence suggest that the informational treatment increases the political tension, with prior right-of-center individuals supporting policies even further to the right while left-of-center individuals do not respond at all.

Many demographic characteristics, opinions and beliefs correlate with an individual's party preferences and we show that beliefs about redistribution being distorting, and about an individual's economic success being the result of effort rather than luck, are more common among those with right-of-center party preferences and that this fact is decisive in shaping the heterogeneous reaction to people being informed that they are relatively richer than they previously believed.

The exact working of this mechanism needs to be further investigated, but one hypothesis is that a person who is informed that he is richer than he thought, and at the same time perceives income to be generated by effort, interprets the information as saying that he has worked harder, relative to others, than what he previously believed. This could, in turn, lead him to feel that he deserves to keep more resources for himself and hence, demand less redistribution (remember that the information about him being richer is, in itself, telling him that redistribution is less of a benefit and/or more of a cost to him than he though). In contrast, a person who believes that income is mainly about luck would not read anything into the information treatment about how hard he has worked compared to others and would hence be unaffected in his feelings of desert.

\section{References}

Alesina, A. and Angeletos, G.-M. (2005). Fairness and redistribution. The American Economic Review, 95(4):960-980.

Alesina, A. and Giuliano, P. (2010). Preferences for redistribution. In Jess Benhabib, Matthew O. Jackson and Alberto Bisin (eds): Handbook of Social Economics, 1A:93-131.

Alesina, A., Roubini, N., and Cohen, G. (1997). Political Cycles and the Macroeconomy. MIT Press.

Alesina, A., Tella, R. D., and MacCulloch, R. (2004). Inequality and happiness: Are Europeans and Americans different? Journal of Public Economics, 88(9-10):2009-2042.

Benabou, R. and Tirole, J. (2006). Belief in a just world and redistributive politics. The Quarterly Journal of Economics, 121(2):699-746.

Bolton, G. E. and Ockenfels, A. (2000). ERC: A theory of equity, reciprocity, and competition. American Economic Review, 90(1):166-193.

Card, D., Mas, A., Moretti, E., and Saez, E. (2012). Inequality at work: The effect of peer salaries on job satisfaction. American Economic Review, 102(6):2981-3003.

Carlstedt, B. (2000). Cognitive abilities: Aspects of structure, process and measurement. Göteborg Studies in Educational Sciences, 148. 
Cruces, G., Perez-Truglia, R., and Tetaz, M. (2013). Biased perceptions of income distribution and preferences for redistribution: Evidence from a survey experiment. Journal of Public Economics, 98:100-112.

Duflo, E. and Saez, E. (2003). The role of information and social interactions in retirement plan decisions: Evidence from a randomized experiment. The Quarterly Journal of Economics, 118(3):815-842.

Durante, R., Putterman, L., and van der Weele, J. (2014). Preferences for redistribution and perception of fairness: An experimental study. Journal of the European Economic Association, 12(4):1059-1086.

Elinder, M., Jordahl, H., and Poutvaara, P. (2010). Self-interested and prospective: Theory and evidence of pocketbook voting. Working Paper.

Fehr, E. and Schmidt, K. M. (1999). A theory of fairness, competition, and cooperation. The Quarterly Journal of Economics, 114(3):817-868.

Fong, C. (2001). Social preferences, self-interest, and the demand for redistribution. Journal of Public Economics, 82(2):225-246.

Heckman, J. J., Stixrud, J., and Urzua, S. (2006). The effects of cognitive and noncognitive abilities on labor market outcomes and social behavior. Journal of Labor Economics, 24(3):411-482.

Kling, J. R., Liebman, J. B., and Katz, L. F. (2007). Experimental analysis of neighborhood effects. Econometrica, 75:83-119.

Kuziemko, I., Norton, M. I., Saez, E., and Stantcheva, S. (2013). How elastic are preferences for redistribution? Evidence from randomized survey experiments. NBER Working Paper 18865.

Lindqvist, E. and Ostling, R. (2010). Political polarization and the size of government. American Political Science Review, 104(3):543-565.

Lindqvist, E. and Westman, R. (2012). The labor market returns to cognitive and noncognitive ability: Evidence from the swedish enlistment. American Economic Journal: Applied Economics, 3(1):101-128.

Margalit, Y. (2013). Explaining social policy preferences: Evidence from the great recession. American Political Science Review, 107(01):80-103.

Meltzer, A. H. and Richard, S. F. (1981). A rational theory of the size of government. Journal of Political Economy, 89(5):914-927.

Norton, M. I. and Ariely, D. (2011). Building a better America, one wealth quintile at a time. Perspectives on Psychological Science, 6(1):9-12.

Peltzman, S. (1985). An economic interpretation of the history of congressional voting in the twentieth century. The American Economic Review, 75(4):656-678. 
Petersson, O. (1994). Swedish Government and Politics. Publica, Stockholm.

Pettersson-Lidbom, P. (2008). Do parties matter for economic outcomes? A regressiondiscontinuity approach. Journal of the European Economic Association, 6(5):1037-1056.

Piketty, T. (1995). Social mobility and redistributive politics. The Quarterly Journal of Economics, 110(3):551-584.

Powdthavee, N. and Oswald, A. J. (2014). Does money make people right-wing and inegalitarian? A longitudinal study of lottery winners. Warwick University Economics Working Paper 1039.

Romer, T. (1975). Individual welfare, majority voting, and the properties of a linear income tax. Journal of Public Economics, 4(2):163-185.

Sears, D. O. and Funk, C. L. (1990). The limited effect of economic self-interest on the political attitudes of the mass public. Journal of Behavioral Economics, 19(3):247-271. 


\section{Tables and figures}

Figure 1: Stated and Actual Income

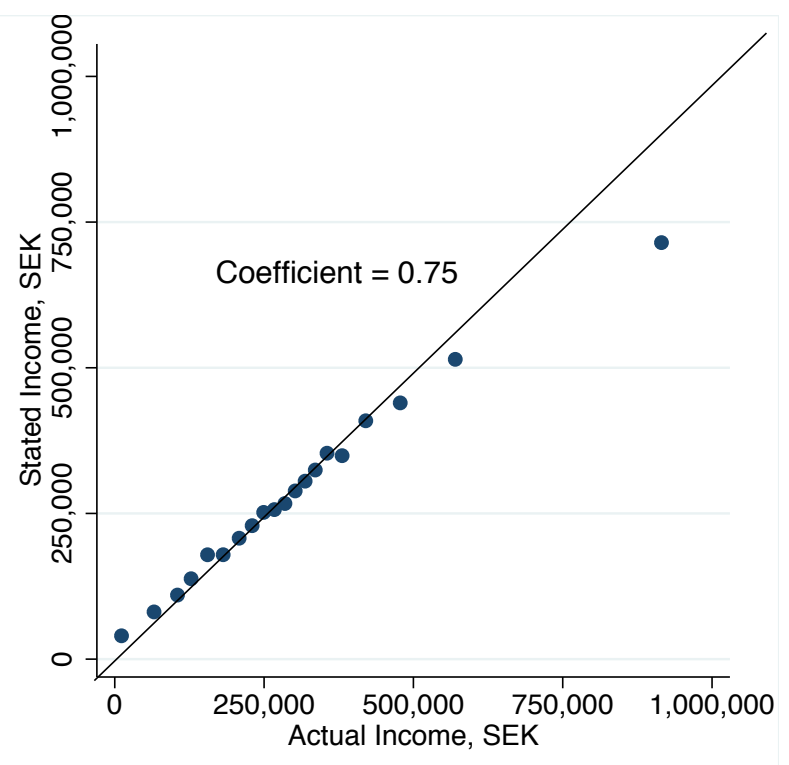

Notes: This figure shows stated annual income in the survey against administrative data income at the individual level. The coefficient of regressing stated income on actual income is 0.75 with a $p$-value of 0.02 for the full sample of 1242 respondents. The solid line represents the 45-degree line. 


\section{Before you answer the questions we want to inform you about the following:}

Imagine that we group all Swedes into 10 groups of equal size such that those in group 1 had the lowest yearly income in 2010 and those in group 10 had the highest yearly income. In the figure below, the numbers 1-10 indicate the groups on the scale. Below the numbers, we have reported the yearly income of the person who was in the middle of that group.

In the previous survey you reported a yearly income for 2010 of X SEK.

In the figure below we have indicated where you income is located on the scale.

\begin{tabular}{|c|c|c|c|c|c|c|c|c|c|c|c|}
\hline \multirow{3}{*}{$\begin{array}{l}\text { Group } 1 \\
\text { (lowest } \\
\text { yearly } \\
\text { income) }\end{array}$} & 1 & 2 & 3 & 4 & 5 & 6 & 7 & 8 & 9 & 10 & \multirow{2}{*}{$\begin{array}{l}\text { Group } 10 \\
\text { (highest yearly } \\
\text { income) }\end{array}$} \\
\hline & & & & & & & & & & & \\
\hline & $\begin{array}{c}0 \\
\text { SEK }\end{array}$ & $\begin{array}{c}67697 \\
\text { SEK }\end{array}$ & $\begin{array}{c}123648 \\
\text { SEK }\end{array}$ & $\begin{array}{c}168498 \\
\text { SEK }\end{array}$ & $\begin{array}{c}207719 \\
\text { SEK }\end{array}$ & $\begin{array}{c}246267 \\
\text { SEK }\end{array}$ & $\begin{array}{c}283546 \\
\text { SEK }\end{array}$ & $\begin{array}{c}326058 \\
\text { SEK }\end{array}$ & $\begin{array}{c}390802 \\
\text { SEK }\end{array}$ & $\begin{array}{c}580388 \\
\text { SEK }\end{array}$ & \\
\hline
\end{tabular}

By income we mean total yearly income, defined as wage and capital income before taxes. Pensions before taxes are also included. Student stipends and other transfers such as unemployment transfers from the government are not included in total yearly income. The income statistics come from Statistics Sweden and are based on the whole Swedish population above age 18.

Notes: The figure above shows the additional piece of text that was presented to the treatment group at the beginning of the second survey. An X marked the exact percentile of the respondent, based on her previously stated income.

Figure 3: Distribution of Bias in the SAmple

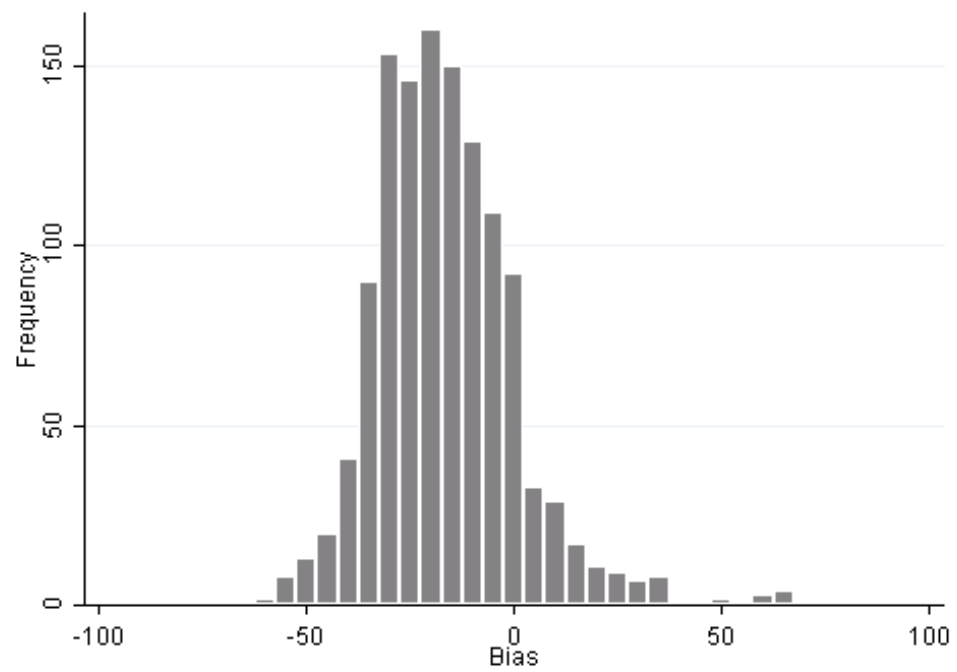

Notes: This figure displays the distribution of bias among the 1242 respondents of the first round. Bias is defined as the perceived minus the actual percentile in the income distribution. Negative values of bias indicate an underestimation of income percentile. The bar width is 5 percentiles. 
Figure 4: Distribution of Bias in the Sample

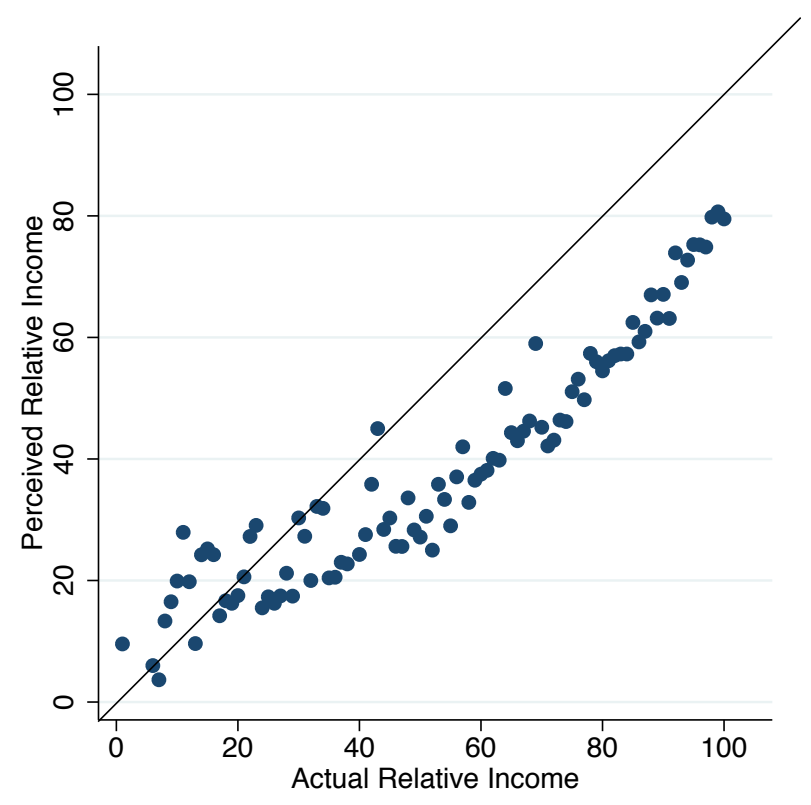

Notes: This figure displays the relation between actual and perceived relative income among the respondents of the first round. We construct 100 equally-sized bins of actual relative income and present mean perceived relative income in each bin. The solid line illustrates the no-bias case and has a slope of one. The number of observations is 1242 . 
Figure 5: Distribution of Bias for Subsamples

(A) EduCATion

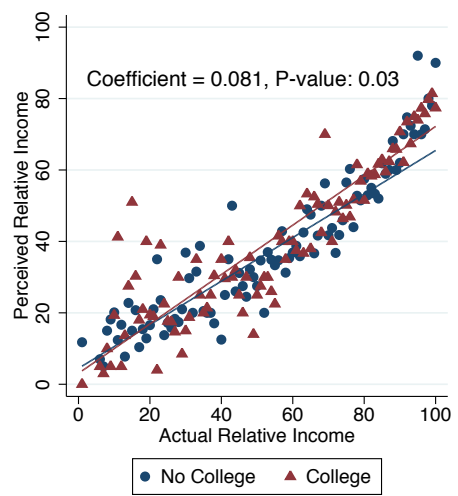

(D) URBAN

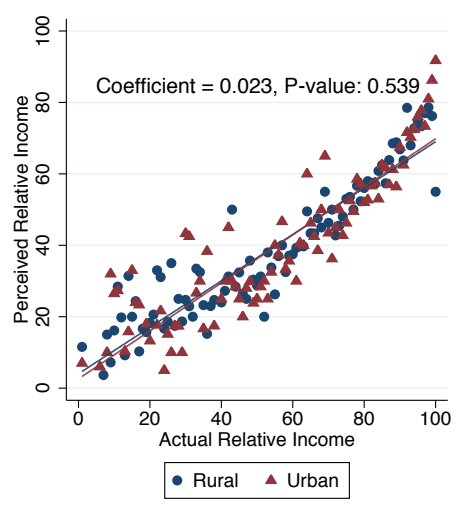

(G) Gender

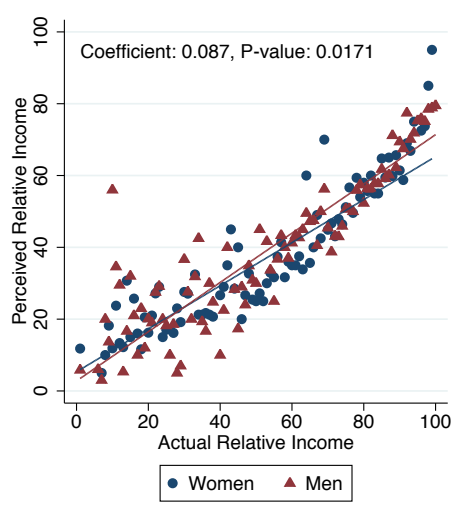

(B) Cognitive Ability

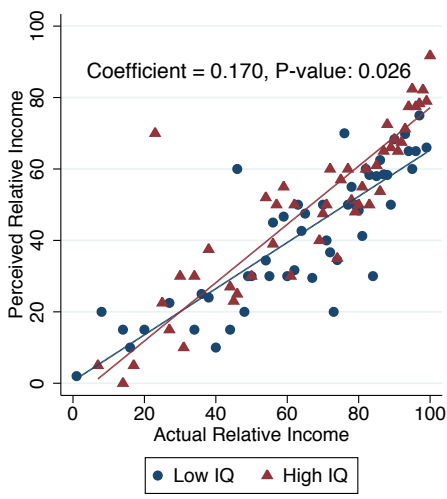

(E) Political Preferences

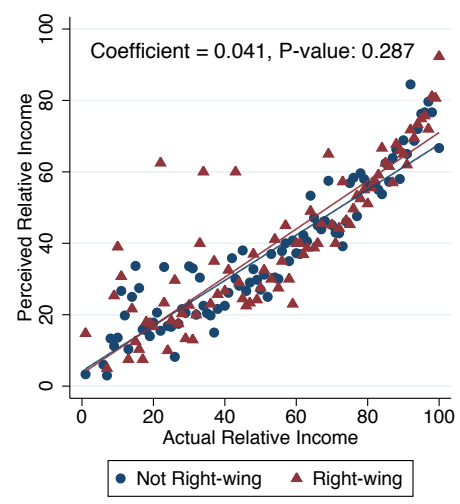

(H) AGE

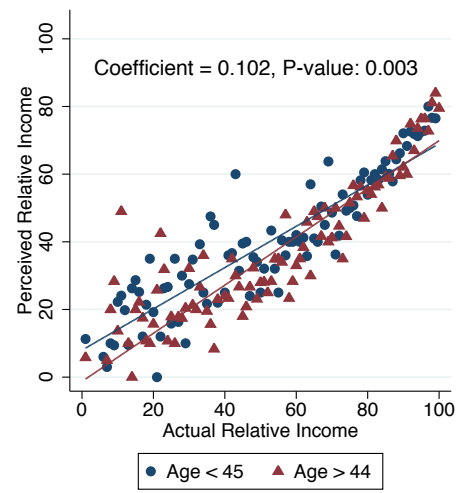

(C) INFORMED

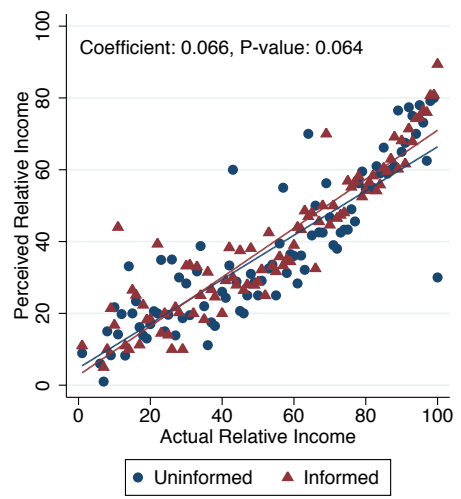

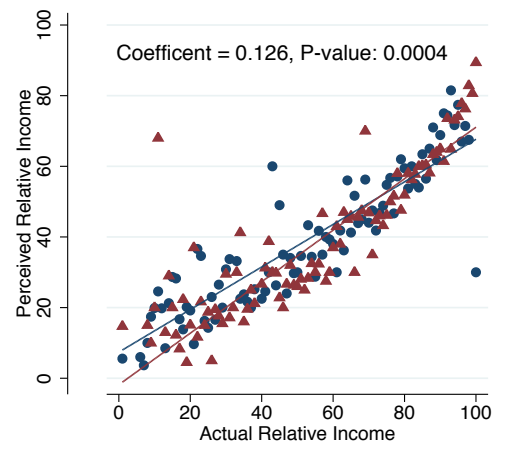

- Net Wealth < Median $\Delta$ Net Wealth $>$ Median

(I) Civil Status

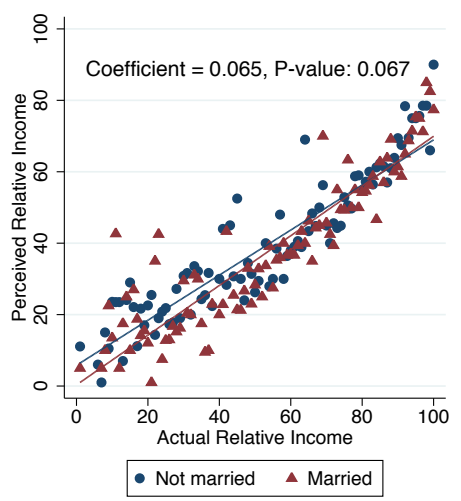

Notes: This figure shows the relation between actual and perceived relative income in various subgroups. For each group, we construct 100 equally-sized bins of the actual relative income and present mean perceived relative income in each bin. The lines in the diagrams correspond to the regression line and the stated coefficient reports the difference in slopes between the two groups. Informed is a dummy variable for self-reporting above median media habits, Urban is a dummy for living in one of the four major metropolitan areas in Sweden, Right-wing is a dummy indicating a preference for one of the four center-right parties in the first survey and Net Wealth is net wealth as reported in administrative records in 2007. The sample in all panels consists of respondents to the first survey. The number of observations in each panel is as follows: (A) 1233, (B) 238, (C) 1240, (D) 1242, (E) 1227, (F) 1242, (G) 1242, (H) 1242 and (I) 1242. 
Figure 6: Graphical RePresentation of treatment efFects

(A) Demand for Redistribution

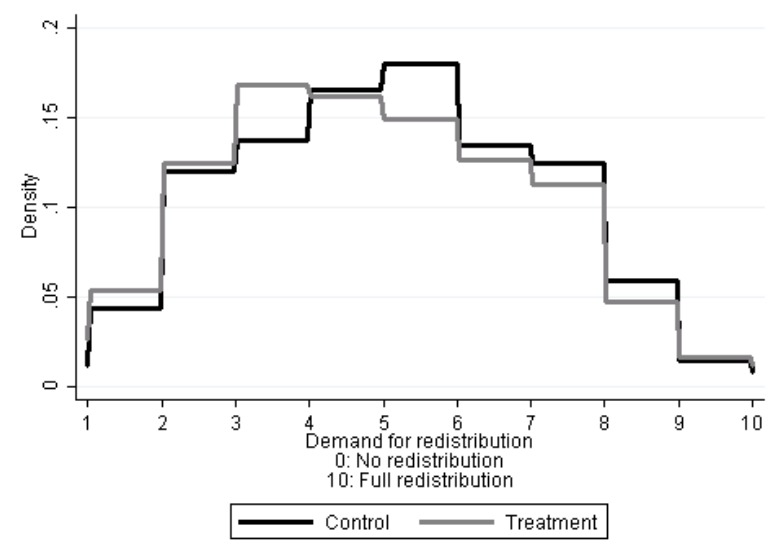

(B) Conservative Party Support

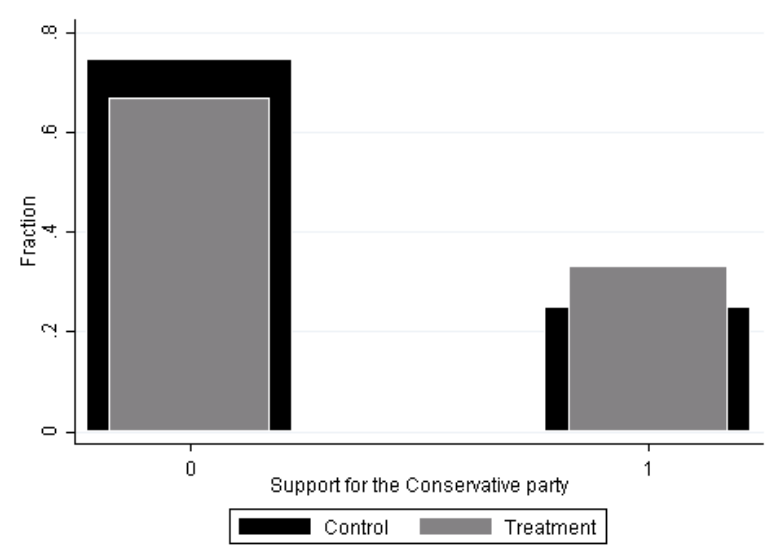

(C) Willingess to Change taxes

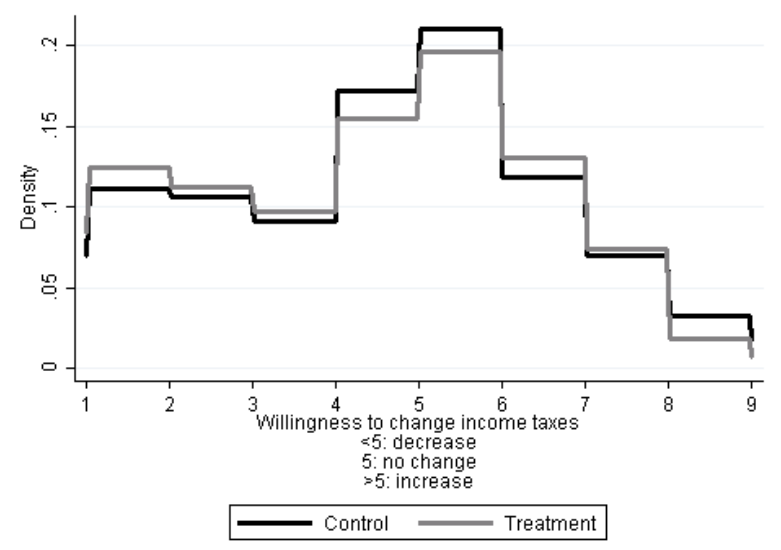

Notes: This figure shows the full distribution of the three outcome variables for the subsample of respondents who underestimated their relative income, i.e. where the treatment informed subjects that they were relatively richer than they thought. The number of observations is 681 in panel A, 597 in panel B and 680 in panel C. 
Figure 7: Graphical Representation of treatment efFects

(A) Demand for Redistribution

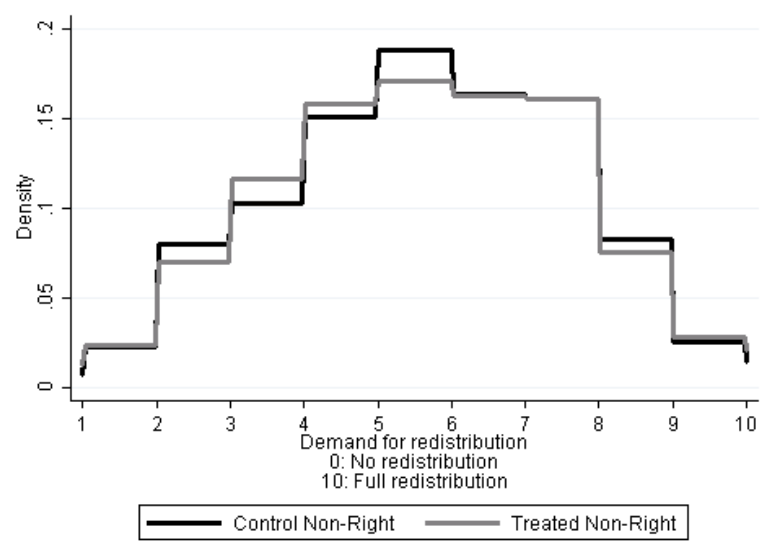

(c) Conservative Party Support

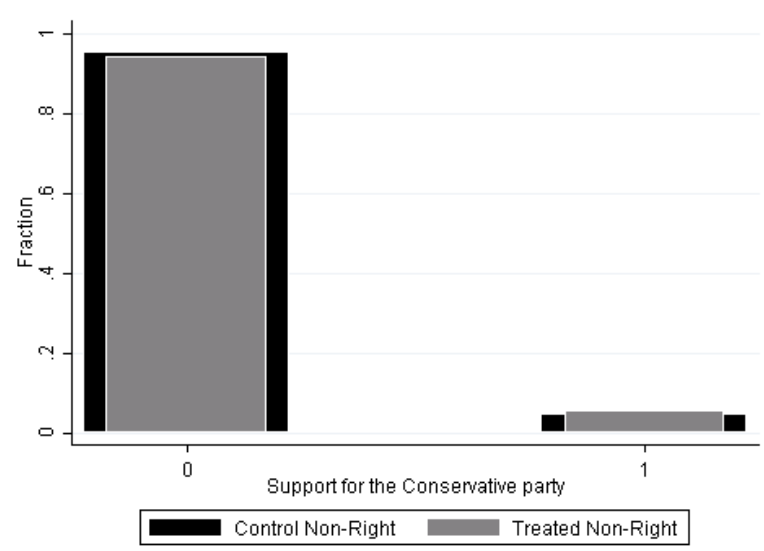

(e) Willingess to change taxes

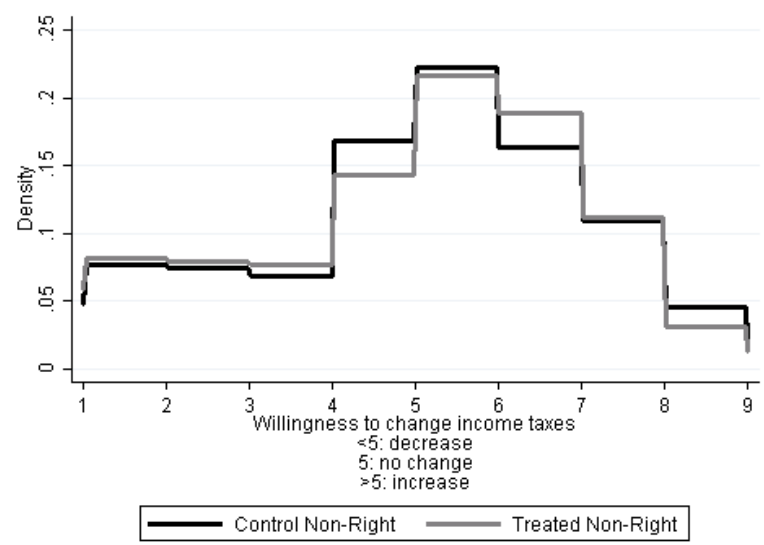

(B) Demand for Redistribution

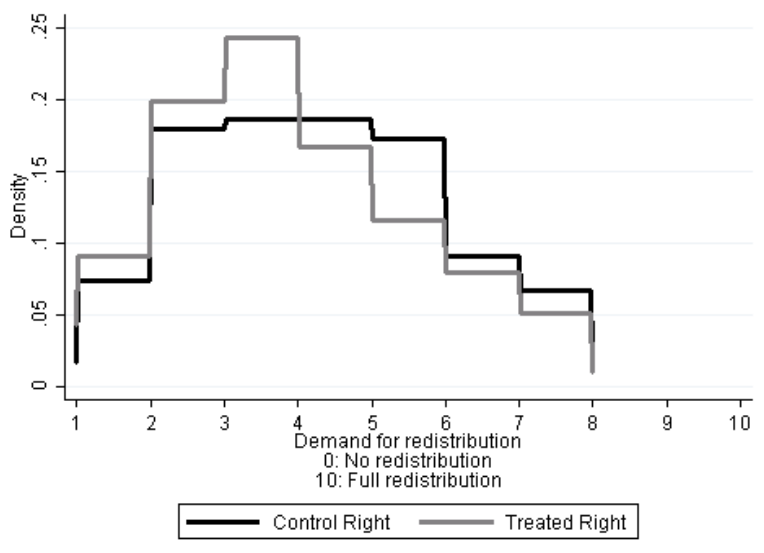

(D) Conservative Party Support

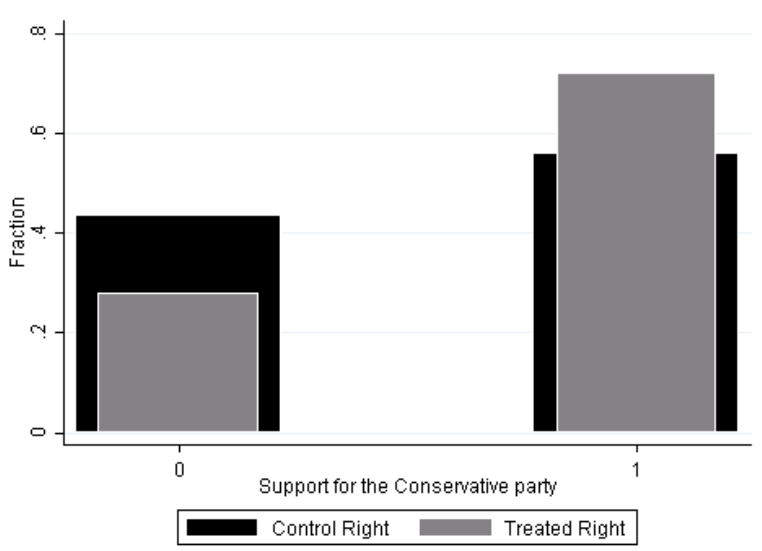

(F) Willingess to Change taxes

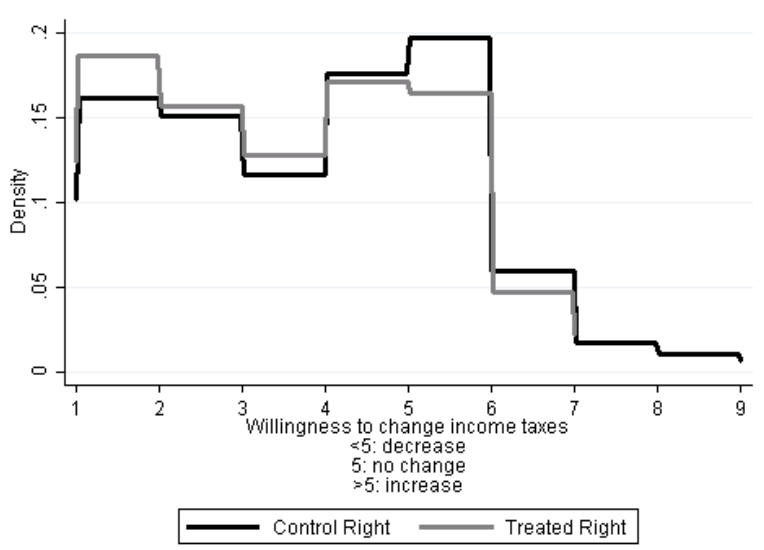

Notes: This figure shows the full distribution of the three outcome variables for the subsample of respondents who underestimated their relative income, i.e. where the treatment informed subjects that they were relatively richer than they thought. The figure also splits the sample between those who had prior right-of-center views (right-hand-side panels) and those who did not (left-hand-side panels). The number of observations in each panel is as follows: (A) 392, (B) 280, (C) 348, (D) 241, (E) 392 and (F) 279. 
Table 1: Comparison Between Population and Survey ReSPONDENTS.

\begin{tabular}{|c|c|c|c|}
\hline & Population & First Survey & Second Survey \\
\hline Age & $\begin{array}{c}45.041 \\
(16.045)\end{array}$ & $\begin{array}{l}45.881^{*} \\
(16.164)\end{array}$ & $\begin{array}{c}46.736^{* * *} \\
(16.127)\end{array}$ \\
\hline Male & $\begin{array}{c}0.505 \\
(0.500)\end{array}$ & $\begin{array}{c}0.514 \\
(0.500)\end{array}$ & $\begin{array}{c}0.510 \\
(0.500)\end{array}$ \\
\hline Married & $\begin{array}{c}0.431 \\
()\end{array}$ & $\begin{array}{c}0.436 \\
(0.496)\end{array}$ & $\begin{array}{c}0.448 \\
(0.497)\end{array}$ \\
\hline Children & $\begin{array}{c}0.845 \\
(1.099)\end{array}$ & $\begin{array}{c}0.705^{* * *} \\
(1.016)\end{array}$ & $\begin{array}{c}0.693^{* * *} \\
(1.023)\end{array}$ \\
\hline Urban & $\begin{array}{l}0.5539 \\
(0.497)\end{array}$ & $\begin{array}{c}0.338^{* * *} \\
(0.473)\end{array}$ & $\begin{array}{c}0.337^{* * *} \\
(0.473)\end{array}$ \\
\hline Primary School & $\begin{array}{c}0.199 \\
(0.399)\end{array}$ & $\begin{array}{c}0.120^{* * *} \\
(0.325)\end{array}$ & $\begin{array}{c}0.112^{* * *} \\
(0.316)\end{array}$ \\
\hline High School & $\begin{array}{c}0.469 \\
(0.499)\end{array}$ & $\begin{array}{l}0.442^{*} \\
(0.497)\end{array}$ & $\begin{array}{c}0.417^{* * *} \\
(0.493)\end{array}$ \\
\hline College Education & $\begin{array}{c}0.332 \\
(0.471)\end{array}$ & $\begin{array}{c}0.438^{* * *} \\
(0.496)\end{array}$ & $\begin{array}{c}0.471^{* * *} \\
(0.499)\end{array}$ \\
\hline Wage Earnings (in 2009) & $\begin{array}{c}184,231 \\
(215,522)\end{array}$ & $\begin{array}{c}215,736^{* * *} \\
(192,029)\end{array}$ & $\begin{array}{c}219,518^{* * *} \\
(195,789)\end{array}$ \\
\hline Net Wealth (in 2006) & $\begin{array}{c}607,971 \\
(26,600,000)\end{array}$ & $\begin{array}{c}588,597 \\
(1,315,998)\end{array}$ & $\begin{array}{c}612,525 \\
(1,335,350)\end{array}$ \\
\hline Unemployment Insurance (in 2009) & $\begin{array}{c}2908 \\
(15,541)\end{array}$ & $\begin{array}{c}2856 \\
(14,457)\end{array}$ & $\begin{array}{c}2731 \\
(14,618)\end{array}$ \\
\hline Max. observations & $6,684,887$ & 1,242 & 1,001 \\
\hline \multicolumn{4}{|c|}{$\begin{array}{l}\text { Notes: Numbers correspond to means and standard deviations are in parentheses. } \\
\text { All monetary variables are denoted in SEK }(1 \text { USD } \approx 7 \text { SEK). Stars denote p- } \\
\text { values for the test of equal means between the survey responses and the population. } \\
* * *-p<0.01,{ }^{* *}-p<0.05,{ }^{*}-p<0.1 \text {. Because of missing values for some } \\
\text { variables, the number of observations for each variable can differ slightly. Children } \\
\text { denotes the total number of children living in the household. Primary school is } \\
\text { a dummy for having at most completed nine years of education, High School is a } \\
\text { dummy for having completed secondary education, College education is a dummy } \\
\text { for having any post-secondary schooling. Wage earnings and Net wealth are wage } \\
\text { earnings in } 2009 \text { and net wealth in } 2006 \text {, respectively, taken from the Swedish Tax } \\
\text { Registries. Unemployment insurance is the amount of transfers received from UI } \\
\text { in } 2009 \text {, also taken from administrative records. }\end{array}$} \\
\hline
\end{tabular}


Table 2: Responding to the Second Survey and Covariates.

Variable

Survey Data:

Treatment

Bias

Informed

Luck

No distort

Just

Care

Right

Administrative Data:

Age

Male

Married

Children

Urban

College Education

Total Taxable Income

Wage Earnings

Net Wealth

Unemployment Insurance

Welfare

IQ
(1)

(2)

\begin{tabular}{cc}
-0.033 & -0.026 \\
$(0.022)$ & $(0.022)$ \\
-0.001 & 0.000 \\
$(0.001)$ & $(0.001)$ \\
-0.021 & $-0.043^{*}$ \\
$(0.022)$ & $(0.023)$ \\
$-0.061^{* *}$ & -0.039 \\
$(0.024)$ & $(0.025)$ \\
0.024 & 0.030 \\
$(0.023)$ & $(0.024)$ \\
-0.003 & 0.027 \\
$(0.024)$ & $(0.031)$ \\
-0.027 & -0.046 \\
$(0.024)$ & $(0.032)$ \\
$0.044^{*}$ & 0.026 \\
$(0.023)$ & $(0.026)$ \\
& \\
$0.003^{* * *}$ & $0.003^{* * *}$ \\
$(0.001)$ & $(0.001)$ \\
-0.010 & 0.000 \\
$(0.022)$ & $(0.024)$ \\
$0.042^{*}$ & -0.008 \\
$(0.022)$ & $(0.026)$ \\
-0.009 & -0.001 \\
$(0.011)$ & $(0.012)$ \\
-0.005 & -0.010 \\
$(0.024)$ & $(0.024)$ \\
$0.108^{* * *}$ & $0.111^{* * *}$ \\
$(0.022)$ & $(0.024)$ \\
$0.015^{* * *}$ & 0.004 \\
$(0.004)$ & $(0.007)$ \\
0.008 & 0.002 \\
$(0.005)$ & $(0.009)$ \\
0.001 & 0.000 \\
$(0.001)$ & $(0.001)$ \\
0.000 & 0.000 \\
$(0.047)$ & $(0.047)$ \\
$-0.001^{* * *}$ & $-0.001^{* *}$ \\
$(0.085)$ & $(0.082)$ \\
0.080 & \\
$(0.051)$ & \\
\hline & \\
\hline &
\end{tabular}

Max. observations

1,242

1,202

Notes: For each row, the first column shows coefficients from OLS regressions of the form bothrounds $s_{i}=\alpha+\beta$ covariate $_{i}+$ $\varepsilon_{i}$ for individuals who responded to the first survey, where the outcome variable is a dummy for responding to the second round of the survey conditional on having responded to the first. The second column shows coefficients when including all covariates in one regression. Robust standard errors are in parentheses. ${ }^{* * *}-p<0.01,{ }^{* *}-p<0.05,{ }^{*}-p<0.1$. Because of missing values for some variables, the number of observations for each variable can differ slightly and the number of observations in the full regressions is lower than the maximum number of observations for the individual covariate-regressions. Bias is the deviation between perceived and actual relative income, Informed is a dummy for above-median usage of news. Luck, No Distort, Just and Care represent the personal views that luck determines success, that taxes do not distort labor supply, that redistribution leads to a more just society and that one supports redistribution because one cares about the consumption of others, respectively. Right is a dummy for preferring one of the four right-ofcenter parties in Sweden, Children denotes the total number of children living in the household and College is a dummy for having any post-secondary schooling. Total Taxable Income, Wage Earnings and Net wealth are taxable income in 2010, wage earnings in 2009 and net wealth in 2006, respectively, taken from the Swedish Tax Registries. Unemployment insurance and Welfare are the amount of unemployment benefits and welfare transfers received in 2009, respectively, also taken from administrative records. $I Q$ is a dummy variable indicating above median cognitive ability, as determined during military enlistment, and is only available for men. 
Table 3: Balance in the Analysis Sample.

Variable

\begin{tabular}{|c|c|c|}
\hline \multicolumn{3}{|l|}{ Survey Data: } \\
\hline Bias & $\begin{array}{c}0.001 \\
(0.001)\end{array}$ & $\begin{array}{c}0.001 \\
(0.002)\end{array}$ \\
\hline Neg. Bias & $\begin{array}{c}0.001 \\
(0.034)\end{array}$ & \\
\hline No Bias & $\begin{array}{l}-0.016 \\
(0.036)\end{array}$ & $\begin{array}{l}-0.041 \\
(0.054)\end{array}$ \\
\hline Pos. Bias & $\begin{array}{c}0.054 \\
(0.069)\end{array}$ & $\begin{array}{c}0.039 \\
(0.118)\end{array}$ \\
\hline Informed & $\begin{array}{l}-0.035 \\
(0.032)\end{array}$ & $\begin{array}{c}-0.036 \\
(0.036)\end{array}$ \\
\hline Luck & $\begin{array}{c}0.019 \\
(0.034)\end{array}$ & $\begin{array}{c}0.008 \\
(0.036)\end{array}$ \\
\hline No Distort & $\begin{array}{c}0.035 \\
(0.032)\end{array}$ & $\begin{array}{c}0.050 \\
(0.034)\end{array}$ \\
\hline Just & $\begin{array}{c}-0.029 \\
(0.033)\end{array}$ & $\begin{array}{l}-0.004 \\
(0.044)\end{array}$ \\
\hline Care & $\begin{array}{l}-0.050 \\
(0.034)\end{array}$ & $\begin{array}{l}-0.049 \\
(0.045)\end{array}$ \\
\hline Right & $\begin{array}{l}-0.000 \\
(0.033)\end{array}$ & $\begin{array}{l}-0.000 \\
(0.037)\end{array}$ \\
\hline Administrative Data: & & \\
\hline Age & $\begin{array}{l}-0.001 \\
(0.001)\end{array}$ & $\begin{array}{c}-0.001 \\
(0.001)\end{array}$ \\
\hline Male & $\begin{array}{l}-0.019 \\
(0.032)\end{array}$ & $\begin{array}{l}-0.019 \\
(0.034)\end{array}$ \\
\hline Married & $\begin{array}{l}-0.008 \\
(0.032)\end{array}$ & $\begin{array}{c}0.013 \\
(0.038)\end{array}$ \\
\hline Children & $\begin{array}{l}-0.010 \\
(0.015)\end{array}$ & $\begin{array}{l}-0.019 \\
(0.017)\end{array}$ \\
\hline Urban & $\begin{array}{c}0.008 \\
(0.033)\end{array}$ & $\begin{array}{c}0.014 \\
(0.035)\end{array}$ \\
\hline College Education & $\begin{array}{l}-0.059^{*} \\
(0.032)\end{array}$ & $\begin{array}{c}-0.066^{*} \\
(0.035)\end{array}$ \\
\hline Total Taxable Income & $\begin{array}{l}-0.002 \\
(0.007)\end{array}$ & $\begin{array}{l}-0.004 \\
(0.012)\end{array}$ \\
\hline Wage Earnings & $\begin{array}{l}-0.001 \\
(0.008)\end{array}$ & $\begin{array}{c}0.009 \\
(0.013)\end{array}$ \\
\hline Net Wealth & $\begin{array}{c}0.001 \\
(0.001)\end{array}$ & $\begin{array}{c}0.002 \\
(0.001)\end{array}$ \\
\hline Unemployment Insurance & $\begin{array}{c}0.000 \\
(0.000)\end{array}$ & $\begin{array}{c}0.000 \\
(0.000)\end{array}$ \\
\hline Welfare & $\begin{array}{c}0.000 \\
(0.000)\end{array}$ & $\begin{array}{c}0.000 \\
(0.000)\end{array}$ \\
\hline IQ & $\begin{array}{l}-0.059 \\
(0.073)\end{array}$ & \\
\hline
\end{tabular}

\begin{tabular}{lcc}
\hline Max. observations & 1,001 & 971
\end{tabular}

Notes: For each row, the first column shows coefficients from OLS regressions of the form treatment $_{i}=\alpha+\beta$ covariate $_{i}+$ $\varepsilon_{i}$ for individuals who responded to the second survey. The second column shows coefficients when including all covariates in one regression. Robust standard errors are in parentheses. ${ }^{* * *}-p<0.01,{ }^{* *}-p<0.05,{ }^{*}-p<0.1$. Because of missing values for some variables, the number of observations for each variable can differ slightly and the number of observations in the full regressions is lower than the maximum number of observations for the individual covariate-regressions. Bias is the deviation between perceived and actual relative income, Neg. Bias, No Bias and Pos. Bias are dummies indicating that the respondent has negative, positive or no bias, Informed is a dummy for above-median usage of news. Luck, No Distort, Just and Care represent the personal views that luck determines success, that taxes do not distort labor supply, that redistribution leads to a more just society and that one supports redistribution because one cares about the consumption of others, respectively. Right is a dummy for preferring one of the four right-of-center parties in Sweden, Children denotes the total number of children living in the household and College is a dummy for having any postsecondary schooling. Total Taxable Income, Wage Earnings and Net wealth are taxable income in 2010, wage earnings in 2009 and net wealth in 2006, respectively, taken from the Swedish Tax Registries. Unemployment insurance and Welfare are the amount of UI benefits and welfare transfers received in 2009, respectively, also taken from administrative records. $I Q$ is a dummy variable for having above-median cognitive ability, as determined during military enlistment, and is only available for men. 
Table 4: Average efFects

\begin{tabular}{lcccc}
\hline & $(1)$ & $(2)$ & $(3)$ & $(4)$ \\
& Outcome Index & Against-Redist & Cons. party & Decrease tax \\
\hline Treated $\times$ Neg. Bias & $0.134^{* *}$ & $0.078^{* *}$ & $0.081^{* *}$ & 0.040 \\
& $(0.057)$ & $(0.037)$ & $(0.037)$ & $(0.038)$ \\
No bias & -0.007 & -0.002 & -0.018 & 0.024 \\
& $(0.072)$ & $(0.049)$ & $(0.050)$ & $(0.051)$ \\
Treated $\times$ No Bias & -0.066 & -0.054 & -0.013 & -0.023 \\
& $(0.085)$ & $(0.059)$ & $(0.056)$ & $(0.062)$ \\
Pos. bias & -0.059 & -0.120 & 0.117 & 0.013 \\
& $(0.152)$ & $(0.089)$ & $(0.114)$ & $(0.104)$ \\
Treated $\times$ Pos. Bias & 0.140 & 0.160 & -0.068 & -0.003 \\
& $(0.193)$ & $(0.124)$ & $(0.139)$ & $(0.136)$ \\
Constant & -0.030 & $0.360^{* * *}$ & $0.251^{* * *}$ & $0.404^{* * *}$ \\
Obs & $(0.039)$ & $(0.026)$ & $(0.027)$ & $(0.027)$ \\
\hline
\end{tabular}

Notes: OLS regressions. Robust standard errors in parentheses. ${ }^{* * *}-p<0.01,{ }^{* *}-p<0.05,{ }^{*}-p<0.1$. This table estimates treatment effects on our four outcome variables. Neg. Bias, No Bias and Pos. Bias are dummies indicating that the respondent has negative, positive or no bias. Outcome Index is a summary measure of the outcome variables in columns 2-4. Against-Redist is a binary indicator for demanding low levels of redistribution. Cons. party is a binary indicator for supporting the Conservative Party. Decrease tax is a binary indicator for wanting to decrease income taxes. See detailed definitions in Section 2.

TABLE 5: HeterogeneOUS EFFECTS BY PRIOR PARTY PREFERENCES

\begin{tabular}{lccccc}
\hline & $(1)$ & $(2)$ & $(3)$ & $(4)$ & $(5)$ \\
& Index & Against-Redist. & Cons. party & Decrease tax & Effort \\
\hline Treated & 0.019 & 0.024 & 0.012 & 0.026 & -0.080 \\
& $(0.054)$ & $(0.044)$ & $(0.024)$ & $(0.047)$ & $(0.187)$ \\
Treated $\times$ Right & $0.280^{* * *}$ & $0.125^{*}$ & $0.147^{* *}$ & 0.046 & $0.588^{* *}$ \\
& $(0.102)$ & $(0.073)$ & $(0.066)$ & $(0.075)$ & $(0.268)$ \\
Right & $0.695^{* * *}$ & $0.267^{* * *}$ & $0.517^{* * *}$ & $0.266^{* * *}$ & $0.585^{* * *}$ \\
& $(0.074)$ & $(0.052)$ & $(0.051)$ & $(0.053)$ & $(0.198)$ \\
Constant & $-0.318^{* * *}$ & $0.250^{* * *}$ & $0.045^{* * *}$ & $0.291^{* * *}$ & $6.095^{* * *}$ \\
& $(0.039)$ & $(0.031)$ & $(0.017)$ & $(0.033)$ & $(0.131)$ \\
Obs & 678 & 678 & 589 & 671 & 674 \\
\hline
\end{tabular}

Notes: OLS regressions. Robust standard errors in parentheses. ${ }^{* * *}-p<0.01,{ }^{* *}-p<0.05,{ }^{*}-p<0.1$. This table estimates heterogeneous treatment effects with respect to prior party preferences. The sample only consists of those who underestimated their relative income. Right is a binary indicator for supporting one of the four right-of-center political parties in Sweden before treatment. Outcome Index is a summary measure of the outcome variables in columns 2-4. Against-Redist is a binary indicator for demanding low levels of redistribution. Cons. party is a binary indicator for supporting the Conservative Party. Decrease tax is a binary indicator for wanting to decrease income taxes. See detailed definitions in Section 2. 
TABle 6: Correlates of CEnTER-Right PREFEREnCES

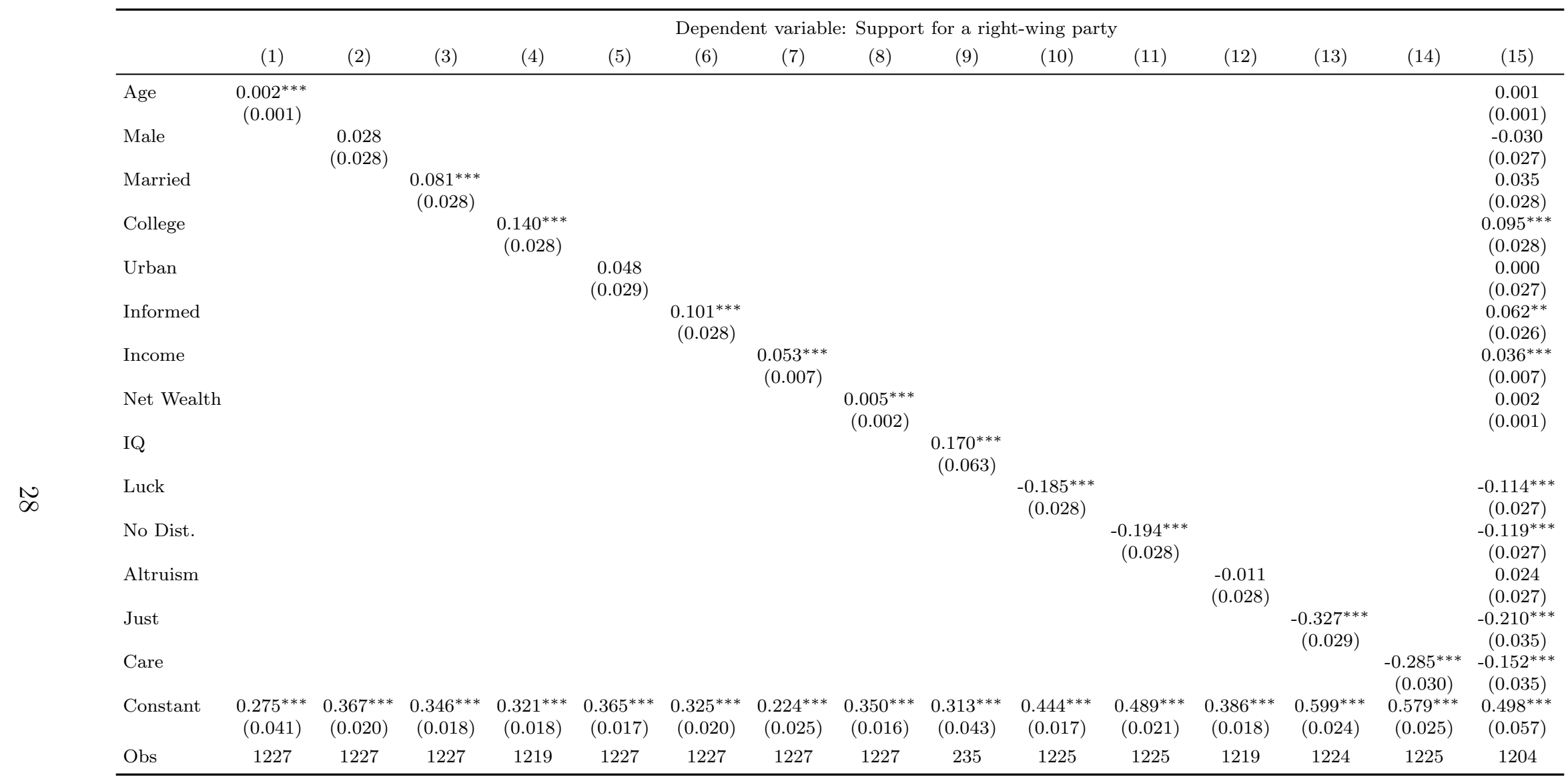

Notes: OLS regressions. Robust standard errors in parentheses. ${ }^{* * *}-p<0.01,{ }^{* *}-p<0.05,{ }^{*}-p<0.1$. This table displays how prior party preferences are correlated with other characteristics, using the full sample from the first survey. Right is a binary indicator for supporting one of the four right-of-center political parties in Sweden before treatment. College is a dummy for having any post-secondary schooling, Informed is a dummy for above-median usage of news, Income is official income in 2010, Net wealth is net wealth in 2006 taken from the Swedish Tax Registries and IQ is a dummy variable for having above-median cognitive ability, as determined during military enlistment, and is only available for men. Altruism is a dummy for above-median willingness to donate to charity. Luck, No Distort, Just and Care represent the personal views that luck determines success, that taxes do not distort labor supply, that redistribution leads to a more just society and that one supports redistribution because one cares about the consumption of others, respectively. 
TABle 7: Heterogeneous EFFECTS By ECONOMIC AND DEMOGRAPHIC CHARACTERISTICS

\begin{tabular}{|c|c|c|c|c|c|c|c|c|}
\hline & \multicolumn{8}{|c|}{ Dependent variable: Outcome Index } \\
\hline & (1) & $(2)$ & $(3)$ & $(4)$ & $(5)$ & $(6)$ & (7) & $(8)$ \\
\hline \multirow[t]{2}{*}{ Treated } & 0.072 & $0.148^{*}$ & 0.105 & 0.091 & $0.145^{* *}$ & 0.133 & $0.131^{* *}$ & 0.118 \\
\hline & $(0.091)$ & $(0.077)$ & $(0.079)$ & $(0.079)$ & $(0.070)$ & $(0.085)$ & $(0.063)$ & $(0.177)$ \\
\hline \multirow[t]{2}{*}{ Treated $\times$ Age } & 0.105 & & & & & & & \\
\hline & $(0.117)$ & & & & & & & \\
\hline \multirow[t]{2}{*}{ Age } & -0.069 & & & & & & & \\
\hline & $(0.082)$ & & & & & & & \\
\hline \multirow[t]{2}{*}{ Treated $\times$ Male } & & -0.021 & & & & & & \\
\hline & & $(0.113)$ & & & & & & \\
\hline \multirow[t]{2}{*}{ Male } & & $0.190^{* *}$ & & & & & & \\
\hline & & $(0.077)$ & & & & & & \\
\hline \multirow[t]{2}{*}{ Treated $\times$ Married } & & & 0.061 & & & & & \\
\hline & & & $(0.114)$ & & & & & \\
\hline \multirow[t]{2}{*}{ Married } & & & -0.003 & & & & & \\
\hline & & & $(0.078)$ & & & & & \\
\hline \multirow[t]{2}{*}{ Treated $\times$ College } & & & & 0.088 & & & & \\
\hline & & & & $(0.114)$ & & & & \\
\hline \multirow[t]{2}{*}{ College } & & & & -0.031 & & & & \\
\hline & & & & $(0.078)$ & & & & \\
\hline \multirow[t]{2}{*}{ Treated $\times$ Urban } & & & & & -0.030 & & & \\
\hline & & & & & $(0.120)$ & & & \\
\hline \multirow[t]{2}{*}{ Urban } & & & & & 0.047 & & & \\
\hline & & & & & $(0.081)$ & & & \\
\hline \multirow[t]{2}{*}{ Treated $\times$ Informed } & & & & & & -0.000 & & \\
\hline & & & & & & $(0.115)$ & & \\
\hline \multirow[t]{2}{*}{ Informed } & & & & & & 0.058 & & \\
\hline & & & & & & $(0.079)$ & & \\
\hline \multirow[t]{2}{*}{ Treated $\times$ Net Wealth } & & & & & & & -0.000 & \\
\hline & & & & & & & $(0.004)$ & \\
\hline \multirow[t]{2}{*}{ Net Wealth } & & & & & & & 0.004 & \\
\hline & & & & & & & $(0.004)$ & \\
\hline \multirow[t]{2}{*}{ Treated $\times$ IQ } & & & & & & & & -0.008 \\
\hline & & & & & & & & $(0.259)$ \\
\hline \multirow[t]{2}{*}{ IQ } & & & & & & & & 0.127 \\
\hline & & & & & & & & $(0.181)$ \\
\hline \multirow[t]{2}{*}{ Constant } & 0.012 & $-0.132^{* *}$ & -0.028 & -0.014 & -0.047 & -0.064 & -0.057 & -0.050 \\
\hline & $(0.066)$ & $(0.053)$ & $(0.053)$ & $(0.056)$ & $(0.049)$ & $(0.060)$ & $(0.045)$ & $(0.124)$ \\
\hline Obs & 687 & 687 & 687 & 687 & 687 & 686 & 687 & 149 \\
\hline
\end{tabular}

Notes: OLS regressions. Robust standard errors in parentheses. ${ }^{* * *}-p<0.01,{ }^{* *}-p<0.05,^{*}-p<0.1$. This table estimates heterogeneous treatment effects on our four outcome variables using various background characteristics. The sample only consists of those who underestimated their relative income. Outcome Index is a summary measure of center-right political preferences. See detailed definitions in Section 2. College is a dummy for having any post-secondary schooling, Informed is a dummy for above-median usage of news, Net wealth is net wealth in 2006, taken from the Swedish Tax Registries and $I Q$ is a dummy variable for having above-median cognitive ability, as determined during military enlistment, and is only available for men. 
TABle 8: Heterogeneous efFects By PRIOR Beliefs

\begin{tabular}{|c|c|c|c|c|c|c|}
\hline & \multicolumn{6}{|c|}{ Dependent variable: Outcome Index } \\
\hline & (1) & $(2)$ & $(3)$ & $(4)$ & $(5)$ & (6) \\
\hline Treated & $\begin{array}{l}0.140^{* *} \\
(0.055)\end{array}$ & $\begin{array}{l}0.221^{* *} \\
(0.089)\end{array}$ & $\begin{array}{c}0.219^{* * *} \\
(0.070)\end{array}$ & $\begin{array}{c}0.139^{* * *} \\
(0.047)\end{array}$ & $\begin{array}{c}0.288^{* * *} \\
(0.089)\end{array}$ & $\begin{array}{c}0.053 \\
(0.057)\end{array}$ \\
\hline Treated $\times$ Redist-Distort & $\begin{array}{c}-0.154^{* *} \\
(0.072)\end{array}$ & & & $\begin{array}{c}-0.127^{* *} \\
(0.061)\end{array}$ & $\begin{array}{l}-0.016 \\
(0.118)\end{array}$ & $\begin{array}{c}-0.132^{*} \\
(0.072)\end{array}$ \\
\hline Redist-Distort & $\begin{array}{c}-0.198^{* * *} \\
(0.052)\end{array}$ & & & $\begin{array}{l}-0.072 \\
(0.046)\end{array}$ & $\begin{array}{l}-0.122 \\
(0.084)\end{array}$ & $\begin{array}{l}-0.066 \\
(0.053)\end{array}$ \\
\hline Treated $\times$ No dist. & & $\begin{array}{l}-0.156 \\
(0.112)\end{array}$ & & & & \\
\hline No Dist. & & $\begin{array}{c}-0.318^{* * *} \\
(0.078)\end{array}$ & & & & \\
\hline Treated $\times$ Luck & & & $\begin{array}{c}-0.260^{* *} \\
(0.117)\end{array}$ & & & \\
\hline Luck & & & $\begin{array}{l}-0.128 \\
(0.081)\end{array}$ & & & \\
\hline Right & & & & $\begin{array}{c}0.773^{* * *} \\
(0.053)\end{array}$ & & \\
\hline Constant & $\begin{array}{l}-0.028 \\
(0.038)\end{array}$ & $\begin{array}{l}0.145^{* *} \\
(0.063)\end{array}$ & $\begin{array}{c}0.010 \\
(0.048)\end{array}$ & $\begin{array}{c}-0.350^{* * *} \\
(0.037)\end{array}$ & $\begin{array}{c}0.352^{* * *} \\
(0.064)\end{array}$ & $\begin{array}{c}-0.308^{* * *} \\
(0.040)\end{array}$ \\
\hline Obs & 687 & 687 & 687 & 678 & 281 & 397 \\
\hline
\end{tabular}

Notes: OLS regressions. Robust standard errors in parentheses. ${ }^{* * *}-p<0.01,{ }^{* *}-p<0.05,{ }^{*}-p<0.1$. Column 5 estimates the same model as Column 1 but restricts the sample to those who had prior centerright preferences, while Column 6 only uses the sample of those who did not have center-right preferences. The sample only consists of those who underestimated their relative income. Redist-Distort is a summary measure of the variables No Dist. and Luck. No. dist is a binary indicator for believing that income taxes do not distort labor supply. Luck is a binary indicator for believing that luck determines economic success in life. Outcome Index is a summary measure of center-right political preferences. See detailed definitions in Section 2. 
TABle 9: Heterogeneous EFFECts By PRIOR VAlues

\begin{tabular}{|c|c|c|c|c|}
\hline & \multicolumn{4}{|c|}{ Dependent variable: Outcome Index } \\
\hline & (1) & $(2)$ & (3) & (4) \\
\hline \multirow[t]{2}{*}{ Treated } & $0.100^{* *}$ & $0.172^{*}$ & 0.139 & $0.183^{* *}$ \\
\hline & (0.050) & (0.096) & (0.101) & $(0.076)$ \\
\hline \multirow[t]{2}{*}{ Treated $\times$ Redist-Moral } & -0.033 & & & \\
\hline & (0.059) & & & \\
\hline \multirow[t]{2}{*}{ Redist-Moral } & $-0.377^{* * *}$ & & & \\
\hline & $(0.042)$ & & & \\
\hline \multirow[t]{2}{*}{ Treated $\times$ Just } & & -0.103 & & \\
\hline & & $(0.112)$ & & \\
\hline \multirow[t]{2}{*}{ Just } & & $-0.665^{* * *}$ & & \\
\hline & & $(0.080)$ & & \\
\hline \multirow[t]{2}{*}{ Treated $\times$ Care } & & & -0.049 & \\
\hline & & & $(0.118)$ & \\
\hline \multirow[t]{2}{*}{ Care } & & & $-0.605^{* * *}$ & \\
\hline & & & $(0.084)$ & \\
\hline \multirow[t]{2}{*}{ Treated $\times$ Altruism } & & & & -0.074 \\
\hline & & & & $(0.114)$ \\
\hline \multirow[t]{2}{*}{ Altruism } & & & & $-0.214^{* * *}$ \\
\hline & & & & $(0.079)$ \\
\hline \multirow[t]{2}{*}{ Constant } & -0.014 & $0.420^{* * *}$ & $0.394^{* * *}$ & 0.049 \\
\hline & $(0.035)$ & $(0.069)$ & $(0.073)$ & $(0.050)$ \\
\hline Obs & 685 & 685 & 685 & 683 \\
\hline
\end{tabular}

Notes: OLS regressions. Robust standard errors in parentheses. ${ }^{* * *}-p<0.01,{ }^{* *}-p<0.05,{ }^{*}-p<0.1$. The sample only consists of those who underestimated their relative income. Redist-Moral is a summary measure of the variables Just and Care. Just is a binary indicator for expressing that one supports redistribution because it leads to a more just society. Care is a binary indicator for expressing that one supports redistribution because one cares about the welfare of others. Altruism is a dummy for above-median willingness to donate to charity. Outcome Index is a summary measure of center-right political preferences. See detailed definitions in Section 2. 
TABle 10: The EFFect of treatment By Size of BIAS

\begin{tabular}{lcccc}
\hline & $(1)$ & $(2)$ & $(3)$ & $(4)$ \\
& Outcome Index & Against-Redist & Cons. party & Decrease tax \\
\hline Treated & 0.121 & 0.084 & 0.066 & 0.019 \\
& $(0.097)$ & $(0.062)$ & $(0.062)$ & $(0.063)$ \\
Medium Bias & -0.105 & -0.070 & -0.067 & -0.043 \\
& $(0.090)$ & $(0.059)$ & $(0.062)$ & $(0.062)$ \\
High Bias & 0.043 & 0.044 & 0.018 & -0.011 \\
& $(0.102)$ & $(0.067)$ & $(0.068)$ & $(0.068)$ \\
T $\times$ Medium Bias & 0.036 & 0.044 & 0.014 & 0.026 \\
& $(0.134)$ & $(0.088)$ & $(0.087)$ & $(0.090)$ \\
T $\times$ High Bias & -0.006 & -0.080 & 0.042 & 0.041 \\
& $(0.146)$ & $(0.095)$ & $(0.095)$ & $(0.096)$ \\
Constant & -0.003 & $0.374^{* * *}$ & $0.267^{* * *}$ & $0.422^{* * *}$ \\
& $(0.066)$ & $(0.042)$ & $(0.044)$ & $(0.044)$ \\
Obs & 687 & 687 & 597 & 680 \\
\hline
\end{tabular}

Notes: OLS regressions. Robust standard errors in parentheses. ${ }^{* * *}-p<0.01,{ }^{* *}-p<0.05,{ }^{*}-p<0.1$. This table estimates the heterogeneous effect of treatment by size of bias among the sample of respondents who underestimated their relative income. The three categories have the same number of observations. The omitted category is Low Bias. Outcome Index is a summary measure of the outcome variables in columns 2-4. Against-Redist is a binary indicator for demanding low levels of redistribution. Cons. party is a binary indicator for supporting the Conservative Party. Decrease tax is a binary indicator for wanting to decrease income taxes. See detailed definitions in Section 2. 


\section{A Appendix}

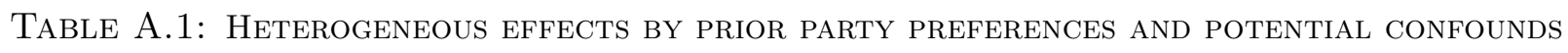

\begin{tabular}{|c|c|c|c|c|c|c|c|c|}
\hline & \multicolumn{8}{|c|}{ Dependent variable: Outcome Index } \\
\hline & (1) & $(2)$ & (3) & (4) & (5) & (6) & $(7)$ & $(8)$ \\
\hline Treated & $\begin{array}{l}-0.060 \\
(0.081)\end{array}$ & $\begin{array}{c}0.021 \\
(0.068)\end{array}$ & $\begin{array}{c}0.004 \\
(0.068)\end{array}$ & $\begin{array}{c}0.027 \\
(0.070)\end{array}$ & $\begin{array}{c}0.070 \\
(0.065)\end{array}$ & $\begin{array}{c}0.036 \\
(0.078)\end{array}$ & $\begin{array}{c}-0.001 \\
(0.059)\end{array}$ & $\begin{array}{c}-0.039 \\
(0.161)\end{array}$ \\
\hline Treated $\times$ Right & $\begin{array}{c}0.283^{* * *} \\
(0.102)\end{array}$ & $\begin{array}{c}0.286^{* * *} \\
(0.101)\end{array}$ & $\begin{array}{c}0.278^{* * *} \\
(0.102)\end{array}$ & $\begin{array}{c}0.300^{* * *} \\
(0.102)\end{array}$ & $\begin{array}{c}0.288^{* * *} \\
(0.102)\end{array}$ & $\begin{array}{c}0.283^{* * *} \\
(0.102)\end{array}$ & $\begin{array}{c}0.270^{* * *} \\
(0.103)\end{array}$ & $\begin{array}{c}0.150 \\
(0.218)\end{array}$ \\
\hline Right & $\begin{array}{c}0.695^{* * *} \\
(0.074)\end{array}$ & $\begin{array}{c}0.689^{* * *} \\
(0.074)\end{array}$ & $\begin{array}{c}0.696^{* * *} \\
(0.075)\end{array}$ & $\begin{array}{c}0.706^{* * *} \\
(0.075)\end{array}$ & $\begin{array}{c}0.696^{* * *} \\
(0.074)\end{array}$ & $\begin{array}{c}0.695^{* * *} \\
(0.075)\end{array}$ & $\begin{array}{c}0.700^{* * *} \\
(0.076)\end{array}$ & $\begin{array}{r}0.917^{* * *} \\
(0.156)\end{array}$ \\
\hline $\mathrm{T} \times$ Age & $\begin{array}{c}0.131 \\
(0.098)\end{array}$ & & & & & & & \\
\hline Age & $\begin{array}{l}-0.056 \\
(0.073)\end{array}$ & & & & & & & \\
\hline $\mathrm{T} \times$ Male & & $\begin{array}{c}-0.007 \\
(0.094)\end{array}$ & & & & & & \\
\hline Male & & $\begin{array}{c}0.171^{* *} \\
(0.069)\end{array}$ & & & & & & \\
\hline $\mathrm{T} \times$ Married & & & $\begin{array}{c}0.032 \\
(0.096)\end{array}$ & & & & & \\
\hline Married & & & $\begin{array}{l}-0.023 \\
(0.070)\end{array}$ & & & & & \\
\hline $\mathrm{T} \times$ College & & & & $\begin{array}{l}-0.042 \\
(0.096)\end{array}$ & & & & \\
\hline College & & & & $\begin{array}{l}-0.100 \\
(0.070)\end{array}$ & & & & \\
\hline $\mathrm{T} \times$ Urban & & & & & $\begin{array}{l}-0.153 \\
(0.098)\end{array}$ & & & \\
\hline Urban & & & & & $\begin{array}{c}0.065 \\
(0.071)\end{array}$ & & & \\
\hline $\mathrm{T} \times$ Informed & & & & & & $\begin{array}{c}-0.034 \\
(0.098)\end{array}$ & & \\
\hline Informed & & & & & & $\begin{array}{l}-0.002 \\
(0.072)\end{array}$ & & \\
\hline $\mathrm{T} \times$ Net Wealth & & & & & & & $\begin{array}{c}0.003 \\
(0.004)\end{array}$ & \\
\hline Net Wealth & & & & & & & $\begin{array}{l}-0.001 \\
(0.003)\end{array}$ & \\
\hline $\mathrm{T} \times \mathrm{IQ}$ & & & & & & & & $\begin{array}{c}0.277 \\
(0.205)\end{array}$ \\
\hline IQ & & & & & & & & $\begin{array}{l}-0.150 \\
(0.149)\end{array}$ \\
\hline Constant & $\begin{array}{c}-0.284^{* * *} \\
(0.061)\end{array}$ & $\begin{array}{c}-0.408^{* * *} \\
(0.050)\end{array}$ & $\begin{array}{c}-0.308^{* * *} \\
(0.049)\end{array}$ & $\begin{array}{c}-0.272^{* * *} \\
(0.052)\end{array}$ & $\begin{array}{c}-0.341^{* * *} \\
(0.047)\end{array}$ & $\begin{array}{c}-0.317^{* * *} \\
(0.058)\end{array}$ & $\begin{array}{c}-0.314^{* * *} \\
(0.042)\end{array}$ & $\begin{array}{r}-0.286^{* *} \\
(0.115)\end{array}$ \\
\hline Obs & 678 & 678 & 678 & 678 & 678 & 678 & 678 & 147 \\
\hline
\end{tabular}

Notes: OLS regressions. Robust standard errors in parentheses. ${ }^{* *}-p<0.01,{ }^{* *}-p<0.05,{ }^{*}-p<0.1$. This table estimates heterogeneous treatment effects on Outcome Index, a summary measure of right-ofcenter political preferences. The sample consists of those who underestimated their relative income. Right is a dummy for supporting a right-of-center party before treatment. College is a dummy for having any post-secondary schooling, Informed is a dummy for above-median usage of news, Net wealth is net wealth in 2006, taken from the Swedish Tax Registries and $I Q$ is a dummy for having above-median cognitive ability, as determined during military enlistment, and is only available for men. 
TABle A.2: Robustness to USIng 5 PeRCentage POINT CUtofF

\begin{tabular}{lcccccccc}
\hline & $(1)$ & $(2)$ & $(3)$ & $(4)$ & $(5)$ & $(6)$ & $(7)$ & $(8)$ \\
& \multicolumn{2}{c}{ Outcome Index } & \multicolumn{2}{c}{ Against-Redist } & Cons. Party & \multicolumn{2}{c}{ Decrease tax } \\
\hline Treated & $0.114^{* *}$ & 0.010 & $0.063^{*}$ & 0.006 & $0.059^{*}$ & 0.001 & 0.045 & 0.039 \\
& $(0.053)$ & $(0.051)$ & $(0.035)$ & $(0.042)$ & $(0.035)$ & $(0.022)$ & $(0.036)$ & $(0.044)$ \\
Treated $\times$ Right & & $0.238^{* *}$ & & $0.129^{*}$ & & $0.120^{*}$ & & 0.022 \\
& & $(0.096)$ & & $(0.069)$ & & $(0.063)$ & & $(0.071)$ \\
Right & & $0.704^{* * *}$ & & $0.263^{* * *}$ & & $0.524^{* * *}$ & $0.272^{* * *}$ \\
& & $(0.069)$ & & $(0.049)$ & & $(0.048)$ & $(0.049)$ \\
Constant & -0.024 & $-0.312^{* * *}$ & $0.372^{* * *}$ & $0.265^{* * *}$ & $0.260^{* * *}$ & $0.051^{* * *}$ & $0.397^{* * *}$ & $0.284^{* * *}$ \\
& $(0.036)$ & $(0.036)$ & $(0.024)$ & $(0.029)$ & $(0.025)$ & $(0.017)$ & $(0.025)$ & $(0.030)$ \\
Obs & 778 & 769 & 778 & 769 & 670 & 662 & 768 & 759 \\
\hline
\end{tabular}

Notes: OLS regressions. Robust standard errors in parentheses. ${ }^{* * *}-p<0.01,{ }^{* *}-p<0.05,{ }^{*}-p<0.1$. This table provides treatment effect estimates on the sample of respondents who underestimate their income, defining the sample with a cutoff of 5 percentage points instead of 10. Outcome Index is a summary measure of the three other outcome variables. Against-Redist is a binary indicator for demanding low levels of redistribution. Cons. party is a binary indicator for supporting the Conservative Party. Decrease tax is a binary indicator for wanting to decrease income taxes. Right is a binary indicator for supporting one of the four right-of-center political parties in Sweden before treatment. See detailed definitions in Section 2.

TABle A.3: Robustness to Using 15 PerCentage Point CUtoff

\begin{tabular}{lcccccccc}
\hline & $(1)$ & $(2)$ & $(3)$ & $(4)$ & $(5)$ & $(6)$ & $(7)$ & $(8)$ \\
& Outcome Index & \multicolumn{2}{c}{ Against-Redist } & Cons. Party & \multicolumn{2}{c}{ Decrease tax } \\
\hline Treated & $0.145^{* *}$ & 0.047 & $0.068^{*}$ & 0.021 & $0.100^{* *}$ & 0.029 & 0.044 & 0.041 \\
& $(0.062)$ & $(0.058)$ & $(0.041)$ & $(0.047)$ & $(0.040)$ & $(0.025)$ & $(0.041)$ & $(0.050)$ \\
Treated $\times$ Right & & $0.254^{* *}$ & & 0.109 & & $0.156^{* *}$ & & 0.025 \\
& & $(0.112)$ & & $(0.079)$ & & $(0.072)$ & & $(0.082)$ \\
Right & & $0.715^{* * *}$ & & $0.290^{* * *}$ & & $0.514^{* * *}$ & $0.266^{* * *}$ \\
& & $(0.081)$ & & $(0.056)$ & & $(0.056)$ & & $(0.058)$ \\
Constant & -0.050 & $-0.348^{* * *}$ & $0.355^{* * *}$ & $0.235^{* * *}$ & $0.238^{* * *}$ & $0.038^{* *}$ & $0.394^{* * *}$ & $0.280^{* * *}$ \\
& $(0.042)$ & $(0.040)$ & $(0.028)$ & $(0.033)$ & $(0.029)$ & $(0.017)$ & $(0.029)$ & $(0.035)$ \\
Obs & 578 & 570 & 578 & 570 & 507 & 500 & 575 & 567 \\
\hline
\end{tabular}

Notes: OLS regressions. Robust standard errors in parentheses. ${ }^{* * *}-p<0.01,{ }^{* *}-p<0.05,{ }^{*}-p<0.1$. This table provides treatment effect estimates on the sample of respondents who underestimate their income, defining the sample with a cutoff of 15 percentage points instead of 10 . Outcome Index is a summary measure of the three other outcome variables. Against-Redist is a binary indicator for demanding low levels of redistribution. Cons. party is a binary indicator for supporting the Conservative Party. Decrease tax is a binary indicator for wanting to decrease income taxes. Right is a binary indicator for supporting one of the four right-of-center political parties in Sweden before treatment. See detailed definitions in Section 2. 
TABLe A.4: Weighted estimates

\begin{tabular}{lcccccccc}
\hline & $(1)$ & $(2)$ & $(3)$ & $(4)$ & $(5)$ & $(6)$ & $(7)$ & $(8)$ \\
& \multicolumn{2}{c}{ Outcome Index } & \multicolumn{2}{c}{ Against-Redist } & \multicolumn{2}{c}{ Cons. } & Party & \multicolumn{2}{c}{ Decrease tax } \\
\hline Treated & $0.134^{* *}$ & 0.002 & $0.090^{* *}$ & 0.027 & $0.071^{*}$ & 0.005 & 0.029 & -0.001 \\
& $(0.062)$ & $(0.059)$ & $(0.042)$ & $(0.051)$ & $(0.043)$ & $(0.027)$ & $(0.043)$ & $(0.053)$ \\
Treated $\times$ Right & & $0.321^{* * *}$ & & $0.148^{*}$ & & $0.140^{*}$ & & 0.080 \\
& & $(0.111)$ & & $(0.084)$ & & $(0.073)$ & & $(0.086)$ \\
Right & & $0.637^{* * *}$ & & $0.221^{* * *}$ & & $0.534^{* * *}$ & & $0.215^{* * *}$ \\
& & $(0.080)$ & & $(0.059)$ & & $(0.056)$ & & $(0.060)$ \\
Mean & -0.046 & -0.304 & 0.343 & 0.254 & 0.257 & 0.049 & 0.399 & 0.311 \\
Obs & 687 & 678 & 687 & 678 & 597 & 589 & 680 & 671 \\
\hline
\end{tabular}

Notes: Weighted OLS regressions. Robust standard errors in parentheses. ${ }^{* * *}-p<0.01,{ }^{* *}-p<0.05$, ${ }^{*}-p<0.1$. This table provides treatment effect estimates weighted by the sampling probability of each observation. Outcome Index is a summary measure of the three other outcome variables. Against-Redist is a binary indicator for demanding low levels of redistribution. Cons. party is a binary indicator for supporting the Conservative party. Decrease tax is a binary indicator for wanting to decrease income taxes. See detailed definitions in Section 2.

TABle A.5: Alternative Definition of Right-OF-CEnTER PARTy PREFEREnCES

\begin{tabular}{lcccccccc}
\hline & $(1)$ & $(2)$ & $(3)$ & $(4)$ & $(5)$ & $(6)$ & $(7)$ & $(8)$ \\
& \multicolumn{2}{c}{ Outcome Index } & \multicolumn{2}{c}{ Against-Redist } & Cons. Party & \multicolumn{2}{c}{ Decrease tax } \\
\hline Treated & -0.024 & 0.023 & -0.015 & 0.041 & -0.007 & $-0.029^{*}$ & 0.022 & 0.041 \\
& $(0.054)$ & $(0.053)$ & $(0.044)$ & $(0.048)$ & $(0.024)$ & $(0.017)$ & $(0.047)$ & $(0.051)$ \\
Treated $\times$ Right SD & $0.268^{* * *}$ & & $0.163^{* *}$ & & $0.137^{* *}$ & & 0.024 & \\
& $(0.096)$ & & $(0.070)$ & & $(0.064)$ & & $(0.073)$ \\
Right SD & $0.708^{* * *}$ & & $0.280^{* * *}$ & & $0.451^{* * *}$ & & $0.319^{* * *}$ \\
& $(0.071)$ & & $(0.051)$ & & $(0.050)$ & & $(0.051)$ \\
Treated $\times$ Right Left & & $0.276^{* * *}$ & & 0.108 & & $0.188^{* * *}$ & \\
& & $(0.101)$ & & $(0.075)$ & & $(0.064)$ & \multicolumn{2}{c}{0.031} \\
Right Left & & $0.874^{* * *}$ & & $0.372^{* * *}$ & & $0.532^{* * *}$ & & $0.384^{* * *}$ \\
& & $(0.073)$ & & $(0.052)$ & & $(0.051)$ & & $(0.054)$ \\
Constant & $-0.354^{* * *}$ & $-0.497^{* * *}$ & $0.232^{* * *}$ & $0.145^{* * *}$ & $0.049^{* * *}$ & $0.029^{*}$ & $0.254^{* * *}$ & $0.172^{* * *}$ \\
& $(0.039)$ & $(0.036)$ & $(0.031)$ & $(0.031)$ & $(0.018)$ & $(0.017)$ & $(0.032)$ & $(0.033)$ \\
Obs & 678 & 525 & 678 & 525 & 589 & 453 & 671 & 520 \\
\hline
\end{tabular}

Notes: OLS regressions. Robust standard errors in parentheses. ${ }^{* * *}-p<0.01,{ }^{* *}-p<0.05,{ }^{*}-p<0.1$. This table shows the robustness of the reported heterogeneous effect by prior center-right preferences using two alternative definitions of right and left parties. In columns 1, 3, 5 and 7 , we include the Sweden Democrats as a party on the right rather than the non-right. In columns 2, 4, 6 and 8 , we compare only those who stated a preference for a party on the right or left as it is usually defined in Sweden, meaning that we discard those who preferred other parties, did not indicate a preference, or indicated blank votes. Outcome Index is a summary measure of the three other outcome variables. Against-Redist is a binary indicator for demanding low levels of redistribution. Cons. party is a binary indicator for supporting the Conservative Party. Decrease tax is a binary indicator for wanting to decrease income taxes. See detailed definitions in Section 2. 
TABle A.6: Robustness to ATtrition

\begin{tabular}{lccccc}
\hline & $(1)$ & $(2)$ & $(3)$ & $(4)$ & $(5)$ \\
& Outcome Index & Against-Redist & Cons. party & Decrease tax & Cons. party \\
\hline Treated & $0.167^{* * *}$ & $0.102^{* *}$ & $0.081^{* *}$ & 0.050 & $0.136^{* * *}$ \\
& $(0.061)$ & $(0.040)$ & $(0.037)$ & $(0.041)$ & $(0.033)$ \\
Constant & -0.062 & $0.338^{* * *}$ & $0.251^{* * *}$ & $0.392^{* * *}$ & $0.190^{* * *}$ \\
& $(0.044)$ & $(0.029)$ & $(0.027)$ & $(0.030)$ & $(0.021)$ \\
Obs & 597 & 597 & 597 & 592 & 687 \\
\hline
\end{tabular}

Notes: OLS regressions. Robust standard errors in parentheses. ${ }^{* * *}-p<0.01,{ }^{* *}-p<0.05,^{*}-p<0.1$. The sample in this table consists only of those who underestimated their relative income. Columns 1 to 4 display treatment effects for the subsample of respondents with non-missing values for Cons. party. Column 5 estimates the treatment effect on Cons. party when recoding all missing values of the outcome variable to zeros. Outcome Index is a summary measure of the outcome variables in columns 2-4. Against-Redist is a binary indicator for demanding low levels of redistribution. Cons. party is a binary indicator for supporting the Conservative Party. Decrease tax is a binary indicator for wanting to decrease income taxes. See detailed definitions in Section 2.

TABle A.7: Robustness tests

\begin{tabular}{lccc}
\hline & $(1)$ & $(2)$ & $(3)$ \\
& Wrong answer & Outcome Index & Outcome Index \\
\hline Right & -0.018 & & \\
Treated & $(0.026)$ & & \\
& & $0.134^{* *}$ & 0.050 \\
Treated $\times$ Below med. & & $(0.067)$ & $(0.153)$ \\
& & -0.011 & -0.182 \\
Below med. & & $(0.123)$ & $(0.183)$ \\
& & $-0.186^{* *}$ & 0.047 \\
Mean & & $(0.082)$ & $(0.132)$ \\
Obs & 0.093 & 0.015 & -0.066 \\
\hline
\end{tabular}

Notes: OLS regressions. Robust standard errors in parentheses. ${ }^{* * *}-p<0.01,{ }^{* *}-p<0.05,^{*}-p<$ 0.1. Wrong answer is a binary indicator for incorrectly identifying oneself as being above or below the median immediately after the treatment information was given. This question only applies to the treatment group. The sample in Column 2 consists of those who underestimated their relative income, and the sample in Column 3 consists of those who correctly estimated their relative income (and hence receive no new information from the treatment). Below med. is a binary indicator for one's true income being below the median. Outcome Index is a summary measure of center-right political preferences. See detailed definitions in Section 2. 
Table A.8: Average effects With controls

\begin{tabular}{lcccccccc}
\hline & $(1)$ & $(2)$ & $(3)$ & $(4)$ & $(5)$ & $(6)$ & $(7)$ & $(8)$ \\
& Outcome Index & \multicolumn{2}{c}{ Against-Redist } & \multicolumn{2}{c}{ Cons. } & Party & \multicolumn{2}{c}{ Decrease tax } \\
\hline Treated $\times$ Neg. Bias & $0.112^{* *}$ & $0.109^{* *}$ & $0.065^{*}$ & $0.055^{*}$ & $0.068^{*}$ & $0.059^{* *}$ & 0.034 & 0.039 \\
& $(0.057)$ & $(0.044)$ & $(0.037)$ & $(0.034)$ & $(0.037)$ & $(0.029)$ & $(0.038)$ & $(0.035)$ \\
No bias & 0.022 & 0.030 & 0.018 & 0.018 & 0.019 & 0.024 & 0.018 & 0.015 \\
& $(0.074)$ & $(0.078)$ & $(0.049)$ & $(0.056)$ & $(0.051)$ & $(0.051)$ & $(0.051)$ & $(0.062)$ \\
Treated $\times$ No Bias & -0.035 & -0.050 & -0.034 & -0.033 & -0.004 & -0.019 & -0.019 & -0.012 \\
& $(0.084)$ & $(0.070)$ & $(0.059)$ & $(0.053)$ & $(0.056)$ & $(0.044)$ & $(0.062)$ & $(0.064)$ \\
Pos. bias & 0.026 & -0.064 & -0.054 & -0.053 & 0.200 & 0.118 & -0.012 & -0.071 \\
& $(0.160)$ & $(0.178)$ & $(0.095)$ & $(0.118)$ & $(0.123)$ & $(0.107)$ & $(0.110)$ & $(0.142)$ \\
Treated $\times$ Pos. Bias & 0.167 & 0.151 & 0.168 & 0.139 & -0.061 & -0.026 & 0.019 & 0.033 \\
& $(0.199)$ & $(0.169)$ & $(0.127)$ & $(0.123)$ & $(0.147)$ & $(0.095)$ & $(0.140)$ & $(0.140)$ \\
Constant & -0.129 & $0.199^{*}$ & $0.345^{* * *}$ & $0.598^{* * *}$ & $0.147^{* *}$ & $0.144^{* *}$ & $0.375^{* * *}$ & $0.565^{* * *}$ \\
& $(0.111)$ & $(0.115)$ & $(0.072)$ & $(0.082)$ & $(0.071)$ & $(0.069)$ & $(0.074)$ & $(0.091)$ \\
Admin. controls & Yes & Yes & Yes & Yes & Yes & Yes & Yes & Yes \\
Survey controls & No & Yes & No & Yes & No & Yes & No & Yes \\
Obs & 996 & 979 & 996 & 979 & 868 & 852 & 981 & 964 \\
\hline
\end{tabular}

Notes: OLS regressions. Robust standard errors in parentheses. ${ }^{* *}-p<0.01,{ }^{* *}-p<0.05,{ }^{*}-p<0.1$. This table evaluates the robustness of the estimated treatment effects on our four outcome variables by including two sets of control variables. Admin. controls consists of data from administrative records and includes age, civil status, number of children, urban/rural home, education, total taxable income in 2010, wage income in 2009, net wealth in 2006 as well as total UI benefits and welfare transfers in 2009. Survey controls consists of variables gathered from our first survey, pre-treatment, and includes bias, media habits, party preference, beliefs about the role of luck and taxation in the economy as well as moral attitudes toward redistribution. Neg. Bias, No Bias and Pos. Bias are dummies indicating that the respondent has negative, positive or no bias. Outcome Index is a summary measure of the three other outcome variables. Against-Redist is a binary indicator for demanding low levels of redistribution. Cons. party is a binary indicator for supporting the Conservative Party. Decrease tax is a binary indicator for wanting to decrease income taxes. See detailed definitions in Section 2. 
TABle A.9: Heterogeneous efFects By Prior PARTy PREFEREnCES With CONTRols

\begin{tabular}{lcccccccc}
\hline & $(1)$ & $(2)$ & $(3)$ & $(4)$ & $(5)$ & $(6)$ & $(7)$ & $(8)$ \\
& Outcome Index & \multicolumn{2}{c}{ Against-Redist } & Cons. Party & \multicolumn{2}{c}{ Decrease tax } \\
\hline Treated & -0.000 & -0.008 & 0.011 & 0.004 & 0.001 & -0.005 & 0.018 & 0.020 \\
& $(0.054)$ & $(0.051)$ & $(0.044)$ & $(0.042)$ & $(0.025)$ & $(0.025)$ & $(0.046)$ & $(0.045)$ \\
Treated $\times$ Right & $0.309^{* * *}$ & $0.282^{* * *}$ & $0.136^{*}$ & $0.118^{*}$ & $0.157^{* *}$ & $0.156^{* *}$ & 0.069 & 0.050 \\
& $(0.102)$ & $(0.096)$ & $(0.073)$ & $(0.070)$ & $(0.067)$ & $(0.066)$ & $(0.076)$ & $(0.073)$ \\
Right & $0.694^{* * *}$ & $0.469^{* * *}$ & $0.246^{* * *}$ & $0.111^{* *}$ & $0.513^{* * *}$ & $0.455^{* * *}$ & $0.286^{* * *}$ & $0.163^{* * *}$ \\
& $(0.075)$ & $(0.076)$ & $(0.052)$ & $(0.054)$ & $(0.051)$ & $(0.055)$ & $(0.054)$ & $(0.056)$ \\
Constant & $-0.257^{* *}$ & 0.216 & $0.340^{* * *}$ & $0.668^{* * *}$ & 0.030 & 0.109 & $0.308^{* * *}$ & $0.553^{* * *}$ \\
& $(0.112)$ & $(0.150)$ & $(0.083)$ & $(0.113)$ & $(0.070)$ & $(0.099)$ & $(0.089)$ & $(0.115)$ \\
Admin controls & Yes & Yes & Yes & Yes & Yes & Yes & Yes & Yes \\
Survey controls & No & Yes & No & Yes & No & Yes & No & Yes \\
Obs & 678 & 673 & 678 & 673 & 589 & 585 & 671 & 666 \\
\hline
\end{tabular}

Notes: OLS regressions. Robust standard errors in parentheses. ${ }^{* * *}-p<0.01,{ }^{* *}-p<0.05,^{*}-p<0.1$. Admin. controls consists of data from administrative records and includes age, civil status, number of children, urban/rural home, education, total taxable income in 2010, wage income in 2009, net wealth in 2006 as well as total UI benefits and welfare transfers in 2009. Survey controls consists of variables gathered from our first survey, pre-treatment, and includes bias, media habits, party preference, beliefs about the role of luck and taxation in the economy as well as moral attitudes toward redistribution. Right is a binary indicator for supporting one of the four right-of-center political parties in Sweden before treatment. Outcome Index is a summary measure of the three other outcome variables. Against-Redist is a binary indicator for demanding low levels of redistribution. Cons. party is a binary indicator for supporting the Conservative party. Decrease tax is a binary indicator for wanting to decrease income taxes. See detailed definitions in Section 2. 


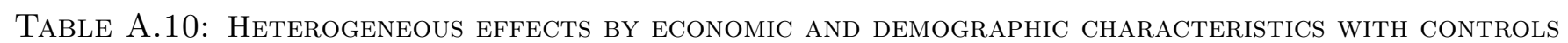

\begin{tabular}{|c|c|c|c|c|c|c|c|c|c|c|c|c|c|c|c|c|}
\hline & & & & & & & Depende & nt variab & le: Outco & me Index & & & & & & \\
\hline & $(1)$ & (2) & (3) & (4) & (5) & (6) & (7) & (8) & $(9)$ & (10) & (11) & (12) & (13) & (14) & (15) & (16) \\
\hline Treated & $\begin{array}{c}0.061 \\
(0.090)\end{array}$ & $\begin{array}{c}0.033 \\
(0.070)\end{array}$ & $\begin{array}{l}0.131^{*} \\
(0.077)\end{array}$ & $0.135^{* *}$ & $\begin{array}{c}0.073 \\
(0.079)\end{array}$ & $\begin{array}{c}0.097 \\
(0.060)\end{array}$ & $\begin{array}{c}0.067 \\
(0.080)\end{array}$ & $\begin{array}{c}0.076 \\
(0.065)\end{array}$ & $0.142^{* *}$ & $0.154^{* * *}$ & $\begin{array}{c}0.113 \\
(0.886)\end{array}$ & $\begin{array}{l}0.121^{*} \\
(0.68)\end{array}$ & $\begin{array}{l}0.112^{*} \\
(0.63)\end{array}$ & $0.090^{*}$ & $\begin{array}{c}0.043 \\
(0.180)\end{array}$ & $\begin{array}{l}-0.084 \\
(0.159)\end{array}$ \\
\hline $\mathrm{T} \times$ Age & $\begin{array}{c}0.092 \\
(0.116)\end{array}$ & $\begin{array}{c}0.136 \\
(0.091)\end{array}$ & & & & & & & & & & & & & & \\
\hline Age & $\begin{array}{c}0.055 \\
(0.134)\end{array}$ & $\begin{array}{c}0.107 \\
(0.113)\end{array}$ & & & & & & & & & & & & & & \\
\hline $\mathrm{T} \times$ Male & & & $\begin{array}{l}-0.035 \\
(0.112)\end{array}$ & $\begin{array}{l}-0.049 \\
(0.089)\end{array}$ & & & & & & & & & & & & \\
\hline $\mathrm{T} \times$ Married & & & & & $\begin{array}{c}0.084 \\
(0.113)\end{array}$ & $\begin{array}{c}0.027 \\
(0.090)\end{array}$ & & & & & & & & & & \\
\hline $\mathrm{T} \times$ College & & & & & & & $\begin{array}{c}0.093 \\
(0.114)\end{array}$ & $\begin{array}{c}0.068 \\
(0.091)\end{array}$ & & & & & & & & \\
\hline $\mathrm{T} \times$ Urban & & & & & & & & & $\begin{array}{l}-0.083 \\
(0.122)\end{array}$ & $\begin{array}{l}-0.125 \\
(0.092)\end{array}$ & & & & & & \\
\hline $\mathrm{T} \times$ Informed & & & & & & & & & & & $\begin{array}{c}-0.006 \\
(0.114)\end{array}$ & $\begin{array}{c}-0.021 \\
(0.091)\end{array}$ & & & & \\
\hline $\mathrm{T} \times$ Net Wealth & & & & & & & & & & & & & $\begin{array}{c}0.000 \\
(0.005)\end{array}$ & $\begin{array}{c}0.003 \\
(0.004)\end{array}$ & & \\
\hline $\mathrm{T} \times \mathrm{IQ}$ & & & & & & & & & & & & & & & $\begin{array}{c}0.012 \\
(0.264)\end{array}$ & $\begin{array}{c}0.338 \\
(0.220)\end{array}$ \\
\hline IQ & & & & & & & & & & & & & & & $\begin{array}{l}-0.051 \\
(0.194)\end{array}$ & $\begin{array}{l}-0.165 \\
(0.183)\end{array}$ \\
\hline Constant & $\begin{array}{c}0.045 \\
(0.179)\end{array}$ & $\begin{array}{c}0.388^{* *} \\
(0.165)\end{array}$ & $\begin{array}{l}-0.081 \\
(0.139)\end{array}$ & $\begin{array}{c}0.175 \\
(0.134)\end{array}$ & $\begin{array}{l}-0.052 \\
(0.139)\end{array}$ & $\begin{array}{c}0.192 \\
(0.136)\end{array}$ & $\begin{array}{l}-0.049 \\
(0.139)\end{array}$ & $\begin{array}{c}0.203 \\
(0.137)\end{array}$ & $\begin{array}{l}-0.081 \\
(0.136)\end{array}$ & $\begin{array}{c}0.176 \\
(0.134)\end{array}$ & $\begin{array}{l}-0.084 \\
(0.142)\end{array}$ & $\begin{array}{c}0.180 \\
(0.136)\end{array}$ & $\begin{array}{c}-0.072 \\
(0.137)\end{array}$ & $\begin{array}{c}0.190 \\
(0.135)\end{array}$ & $\begin{array}{c}0.302 \\
(0.462)\end{array}$ & $\begin{array}{c}0.097 \\
(0.390)\end{array}$ \\
\hline Admin. cont. & Yes & Yes & Yes & Yes & Yes & Yes & Yes & Yes & Yes & Yes & Yes & Yes & Yes & Yes & Yes & Yes \\
\hline Survey cont. & No & Yes & No & Yes & No & Yes & No & Yes & No & Yes & Yes & Yes & No & Yes & No & Yes \\
\hline Obs & 687 & 677 & 687 & 677 & 687 & 677 & 687 & 677 & 687 & 677 & 686 & 677 & 687 & 677 & 149 & 146 \\
\hline
\end{tabular}

Notes: OLS regressions. Robust standard errors in parentheses. ${ }^{* * *}-p<0.01,{ }^{* *}-p<0.05,{ }^{*}-p<0.1$. Outcome Index is a summary measure of center-right political preferences. See detailed definitions in Section 2. Admin. controls consists of data from administrative records and includes age, civil status, number of children, urban/rural home, education, total taxable income in 2010, wage income in 2009 , net wealth in 2006 as well as total UI benefits and welfare transfers in 2009. Survey controls consists of variables gathered from our first survey, pre-treatment, and includes bias, media habits, party preference, beliefs about the role of luck and taxation in the economy as well as moral attitudes toward redistribution. Outcome Index is a summary measure of the three other outcome variables. 
TABle A.11: Heterogeneous EFFECTS By PRIOR BELIEFS With CONTROLS 1

\begin{tabular}{|c|c|c|c|c|c|c|}
\hline & \multicolumn{6}{|c|}{ Dependent variable: Outcome Index } \\
\hline & (1) & (2) & (3) & (4) & (5) & (6) \\
\hline \multirow[t]{2}{*}{ Treated } & $0.122^{* *}$ & $0.112^{* *}$ & $0.187^{* *}$ & $0.164^{* *}$ & $0.198^{* * *}$ & $0.157^{* * *}$ \\
\hline & $(0.055)$ & $(0.044)$ & $(0.090)$ & $(0.072)$ & $(0.069)$ & $(0.054)$ \\
\hline \multirow[t]{2}{*}{$\mathrm{T} \times$ Redist-Distort } & $-0.144^{* *}$ & $-0.098^{*}$ & & & & \\
\hline & $(0.072)$ & $(0.058)$ & & & & \\
\hline \multirow[t]{2}{*}{ Redist-Distort } & $-0.192^{* * *}$ & -0.071 & & & & \\
\hline & $(0.052)$ & $(0.044)$ & & & & \\
\hline \multirow[t]{2}{*}{$\mathrm{T} \times$ No dist. } & & & -0.129 & -0.099 & & \\
\hline & & & $(0.113)$ & $(0.091)$ & & \\
\hline \multirow[t]{2}{*}{ No Dist. } & & & $-0.319^{* * *}$ & $-0.126^{*}$ & & \\
\hline & & & $(0.078)$ & $(0.067)$ & & \\
\hline \multirow[t]{2}{*}{ T $\times$ Luck } & & & & & $-0.259^{* *}$ & -0.155 \\
\hline & & & & & $(0.116)$ & $(0.097)$ \\
\hline \multirow[t]{2}{*}{ Luck } & & & & & -0.113 & -0.025 \\
\hline & & & & & $(0.081)$ & $(0.068)$ \\
\hline \multirow[t]{2}{*}{ Constant } & -0.009 & 0.076 & 0.140 & 0.128 & 0.002 & 0.085 \\
\hline & $(0.133)$ & $(0.130)$ & $(0.145)$ & $(0.138)$ & $(0.139)$ & $(0.134)$ \\
\hline Admin controls & Yes & Yes & Yes & Yes & Yes & Yes \\
\hline Survey controls & No & Yes & No & Yes & No & Yes \\
\hline Obs & 687 & 677 & 687 & 677 & 687 & 677 \\
\hline
\end{tabular}

Notes: OLS regressions. Robust standard errors in parentheses. ${ }^{* * *}-p<0.01,{ }^{* *}-p<0.05,{ }^{*}-p<0.1$. Admin. controls consists of data from administrative records and includes age, civil status, number of children, urban/rural home, education, total taxable income in 2010, wage income in 2009, net wealth in 2006 as well as total UI benefits and welfare transfers in 2009. Survey controls consists of variables gathered from our first survey, pre-treatment, and includes bias, media habits, party preference, beliefs about the role of luck and taxation in the economy as well as moral attitudes toward redistribution. Redist-Distort is a summary measure of the variables No Dist. and Luck. No. dist is a binary indicator for believing that income taxes do not distort labor supply. Luck is a binary indicator for believing that luck determines economic success in life. Outcome Index is a summary measure of center-right political preferences. See detailed definitions in Section 2. 
TABle A.12: Heterogeneous effects by PRior Beliefs With CONTrols 2

\begin{tabular}{|c|c|c|c|c|c|c|}
\hline & $\begin{array}{l}\text { Depenc } \\
(1)\end{array}$ & $\begin{array}{c}\text { dent varia } \\
\text { (2) }\end{array}$ & $\begin{array}{c}\text { ble: Low } \\
\text { (3) }\end{array}$ & $\begin{array}{c}\text { Demand } \mathrm{f} \\
(4)\end{array}$ & $\begin{array}{c}\text { or Redist } \\
\text { (5) }\end{array}$ & $\begin{array}{c}\text { ibution } \\
\quad(6)\end{array}$ \\
\hline Treated & $\begin{array}{c}0.069^{*} \\
(0.036)\end{array}$ & $\begin{array}{c}0.054 \\
(0.033)\end{array}$ & $\begin{array}{l}0.116^{* *} \\
(0.055)\end{array}$ & $\begin{array}{l}0.087^{*} \\
(0.050)\end{array}$ & $\begin{array}{l}0.095^{* *} \\
(0.045)\end{array}$ & $\begin{array}{c}0.066 \\
(0.042)\end{array}$ \\
\hline $\mathrm{T} \times$ Redist-Distort & $\begin{array}{l}-0.068 \\
(0.049)\end{array}$ & $\begin{array}{l}-0.041 \\
(0.044)\end{array}$ & & & & \\
\hline Redist-Distort & $\begin{array}{c}-0.067^{*} \\
(0.035)\end{array}$ & $\begin{array}{l}-0.020 \\
(0.034)\end{array}$ & & & & \\
\hline $\mathrm{T} \times$ No dist. & & & $\begin{array}{l}-0.089 \\
(0.074)\end{array}$ & $\begin{array}{l}-0.060 \\
(0.067)\end{array}$ & & \\
\hline No Dist. & & & $\begin{array}{c}-0.088^{*} \\
(0.051)\end{array}$ & $\begin{array}{l}-0.010 \\
(0.049)\end{array}$ & & \\
\hline $\mathrm{T} \times$ Luck & & & & & $\begin{array}{l}-0.088 \\
(0.078)\end{array}$ & $\begin{array}{c}-0.042 \\
(0.071)\end{array}$ \\
\hline Luck & & & & & $\begin{array}{l}-0.064 \\
(0.055)\end{array}$ & $\begin{array}{l}-0.034 \\
(0.052)\end{array}$ \\
\hline Constant & $\begin{array}{c}0.418^{* * *} \\
(0.087)\end{array}$ & $\begin{array}{c}0.603^{* * *} \\
(0.095)\end{array}$ & $\begin{array}{c}0.453^{* * *} \\
(0.093)\end{array}$ & $\begin{array}{c}0.602^{* * *} \\
(0.098)\end{array}$ & $\begin{array}{c}0.429^{* * *} \\
(0.090)\end{array}$ & $\begin{array}{c}0.615^{* * *} \\
(0.097)\end{array}$ \\
\hline Admin controls & Yes & Yes & Yes & Yes & Yes & Yes \\
\hline Survey controls & No & Yes & No & Yes & No & Yes \\
\hline Obs & 687 & 677 & 687 & 677 & 687 & 677 \\
\hline
\end{tabular}

Notes: OLS regressions. Robust standard errors in parentheses. ${ }^{* * *}-p<0.01,{ }^{* *}-p<0.05,{ }^{*}-p<0.1$. Admin. controls consists of data from administrative records and includes age, civil status, number of children, urban/rural home, education, total taxable income in 2010, wage income in 2009, net wealth in 2006 as well as total UI benefits and welfare transfers in 2009. Survey controls consists of variables gathered from our first survey, pre-treatment, and includes bias, media habits, party preference, beliefs about the role of luck and taxation in the economy as well as moral attitudes toward redistribution. Redist-Distort is a summary measure of the variables No Dist. and Luck. No. dist is a binary indicator for believing that income taxes do not distort labor supply. Luck is a binary indicator for believing that luck determines economic success in life. Against-Redist is a dummy for below-median demand for redistribution. See detailed definitions in Section 2. 
TABle A.13: Heterogeneous efFects by PRIOR Beliefs with CONTROls 3

\begin{tabular}{|c|c|c|c|c|c|c|}
\hline & \multicolumn{2}{|c|}{ Dependent variable } & \multicolumn{4}{|c|}{ Support for the Conservative Party } \\
\hline & (1) & $(2)$ & (3) & $(4)$ & $(5)$ & (6) \\
\hline \multirow[t]{2}{*}{ Treated } & $0.063^{*}$ & $0.060^{* *}$ & 0.064 & 0.076 & $0.088^{*}$ & 0.059 \\
\hline & $(0.036)$ & $(0.029)$ & $(0.060)$ & $(0.049)$ & $(0.047)$ & $(0.038)$ \\
\hline \multirow[t]{2}{*}{$\mathrm{T} \times$ Redist-Distort } & -0.025 & -0.010 & & & & \\
\hline & $(0.048)$ & $(0.037)$ & & & & \\
\hline \multirow[t]{2}{*}{ Redist-Distort } & $-0.115^{* * *}$ & -0.022 & & & & \\
\hline & $(0.036)$ & $(0.029)$ & & & & \\
\hline \multirow[t]{2}{*}{$\mathrm{T} \times$ No dist. } & & & -0.002 & -0.029 & & \\
\hline & & & $(0.075)$ & $(0.060)$ & & \\
\hline \multirow[t]{2}{*}{ No Dist. } & & & $-0.173^{* * *}$ & -0.015 & & \\
\hline & & & $(0.055)$ & $(0.047)$ & & \\
\hline \multirow[t]{2}{*}{$\mathrm{T} \times$ Luck } & & & & & -0.076 & 0.002 \\
\hline & & & & & $(0.074)$ & $(0.060)$ \\
\hline \multirow[t]{2}{*}{ Luck } & & & & & $-0.089^{*}$ & -0.034 \\
\hline & & & & & $(0.054)$ & $(0.044)$ \\
\hline \multirow[t]{2}{*}{ Constant } & $0.184^{* *}$ & 0.054 & $0.264^{* * *}$ & 0.058 & $0.199^{* *}$ & 0.065 \\
\hline & $(0.088)$ & $(0.088)$ & $(0.096)$ & $(0.089)$ & $(0.091)$ & $(0.090)$ \\
\hline Admin controls & Yes & Yes & Yes & Yes & Yes & Yes \\
\hline Survey controls & No & Yes & No & Yes & No & Yes \\
\hline Obs & 597 & 588 & 597 & 588 & 597 & 588 \\
\hline
\end{tabular}

Notes: OLS regressions. Robust standard errors in parentheses. ${ }^{* * *}-p<0.01,{ }^{* *}-p<0.05,{ }^{*}-p<0.1$. Admin. controls consists of data from administrative records and includes age, civil status, number of children, urban/rural home, education, total taxable income in 2010, wage income in 2009, net wealth in 2006 as well as total UI benefits and welfare transfers in 2009. Survey controls consists of variables gathered from our first survey, pre-treatment, and includes bias, media habits, party preference, beliefs about the role of luck and taxation in the economy as well as moral attitudes toward redistribution. Redist-Distort is a summary measure of the variables No Dist. and Luck. No. dist is a binary indicator for believing that income taxes do not distort labor supply. Luck is a binary indicator for believing that luck determines economic success in life. Cons. Party is a dummy for supporting the Conservative Party. See detailed definitions in Section 2. 
TABle A.14: Heterogeneous efFects by PRIOR Beliefs with CONTROls 4

\begin{tabular}{|c|c|c|c|c|c|c|}
\hline & \multicolumn{6}{|c|}{ Dependent variable: Demand for Lower Taxes } \\
\hline & (1) & $(2)$ & $(3)$ & $(4)$ & (5) & $(6)$ \\
\hline Treated & $\begin{array}{c}0.043 \\
(0.037)\end{array}$ & $\begin{array}{c}0.042 \\
(0.035)\end{array}$ & $\begin{array}{c}0.086 \\
(0.057)\end{array}$ & $\begin{array}{c}0.079 \\
(0.053)\end{array}$ & $\begin{array}{l}0.098^{* *} \\
(0.047)\end{array}$ & $\begin{array}{l}0.084^{* *} \\
(0.043)\end{array}$ \\
\hline $\mathrm{T} \times$ Redist-Distort & $\begin{array}{c}-0.103^{* *} \\
(0.048)\end{array}$ & $\begin{array}{l}-0.083^{*} \\
(0.047)\end{array}$ & & & & \\
\hline Redist-Distort & $\begin{array}{c}-0.096^{* * *} \\
(0.036)\end{array}$ & $\begin{array}{l}-0.056 \\
(0.035)\end{array}$ & & & & \\
\hline $\mathrm{T} \times$ No dist. & & & $\begin{array}{l}-0.086 \\
(0.075)\end{array}$ & $\begin{array}{l}-0.070 \\
(0.071)\end{array}$ & & \\
\hline No Dist. & & & $\begin{array}{c}-0.202^{* * *} \\
(0.053)\end{array}$ & $\begin{array}{c}-0.135^{* * *} \\
(0.052)\end{array}$ & & \\
\hline $\mathrm{T} \times$ Luck & & & & & $\begin{array}{c}-0.188^{* *} \\
(0.081)\end{array}$ & $\begin{array}{c}-0.146^{*} \\
(0.080)\end{array}$ \\
\hline Luck & & & & & $\begin{array}{l}-0.010 \\
(0.058)\end{array}$ & $\begin{array}{c}0.019 \\
(0.057)\end{array}$ \\
\hline Constant & $\begin{array}{c}0.435^{* * *} \\
(0.087)\end{array}$ & $\begin{array}{c}0.477^{* * *} \\
(0.102)\end{array}$ & $\begin{array}{c}0.535^{* * *} \\
(0.093)\end{array}$ & $\begin{array}{c}0.539^{* * *} \\
(0.108)\end{array}$ & $\begin{array}{c}0.423^{* * *} \\
(0.092)\end{array}$ & $\begin{array}{c}0.471^{* * *} \\
(0.105)\end{array}$ \\
\hline Admin controls & Yes & Yes & Yes & Yes & Yes & Yes \\
\hline Survey controls & No & Yes & No & Yes & No & Yes \\
\hline Obs & 680 & 670 & 680 & 670 & 680 & 670 \\
\hline
\end{tabular}

Notes: OLS regression. Robust standard errors in parentheses. ${ }^{* * *}-p<0.01,{ }^{* *}-p<0.05,{ }^{*}-p<0.1$. Admin. controls consists of data from administrative records and includes age, civil status, number of children, urban/rural home, education, total taxable income in 2010, wage income in 2009, net wealth in 2006 as well as total UI benefits and welfare transfers in 2009. Survey controls consists of variables gathered from our first survey, pre-treatment, and includes bias, media habits, party preference, beliefs about the role of luck and taxation in the economy as well as moral attitudes toward redistribution. Redist-Distort is a summary measure of the variables No Dist. and Luck. No. dist is a binary indicator for believing that income taxes do not distort labor supply. Luck is a binary indicator for believing that luck determines economic success in life. Decrease Tax is a dummy for wanting to decrease income taxes. See detailed definitions in Section 2. 
TABle A.15: Heterogeneous effects By PRIOR VAlues With CONTROLS 1

\begin{tabular}{|c|c|c|c|c|c|c|c|c|}
\hline & \multicolumn{8}{|c|}{ Dependent variable: Outcome Index } \\
\hline & (1) & $(2)$ & $(3)$ & (4) & $(5)$ & $(6)$ & (7) & $(8)$ \\
\hline Treated & $\begin{array}{l}0.083^{*} \\
(0.050)\end{array}$ & $\begin{array}{l}0.109^{* *} \\
(0.044)\end{array}$ & $\begin{array}{c}0.143 \\
(0.093)\end{array}$ & $\begin{array}{l}0.158^{*} \\
(0.083)\end{array}$ & $\begin{array}{c}0.112 \\
(0.100)\end{array}$ & $\begin{array}{l}0.145^{*} \\
(0.087)\end{array}$ & $\begin{array}{l}0.163^{* *} \\
(0.076)\end{array}$ & $\begin{array}{c}0.091 \\
(0.064)\end{array}$ \\
\hline $\mathrm{T} \times$ Redist-Moral & $\begin{array}{c}-0.024 \\
(0.058)\end{array}$ & $\begin{array}{c}-0.026 \\
(0.052)\end{array}$ & & & & & & \\
\hline Redist-Moral & $\begin{array}{c}-0.381^{* * *} \\
(0.043)\end{array}$ & $\begin{array}{c}-0.243^{* * *} \\
(0.043)\end{array}$ & & & & & & \\
\hline $\mathrm{T} \times$ Just & & & $\begin{array}{c}-0.084 \\
(0.111)\end{array}$ & $\begin{array}{c}-0.068 \\
(0.099)\end{array}$ & & & & \\
\hline Just & & & $\begin{array}{c}-0.665^{* * *} \\
(0.079)\end{array}$ & $\begin{array}{c}-0.423^{* * *} \\
(0.079)\end{array}$ & & & & \\
\hline $\mathrm{T} \times$ Care & & & & & $\begin{array}{c}-0.035 \\
(0.117)\end{array}$ & $\begin{array}{c}-0.046 \\
(0.103)\end{array}$ & & \\
\hline Care & & & & & $\begin{array}{c}-0.615^{* * *} \\
(0.085)\end{array}$ & $\begin{array}{c}-0.365^{* * *} \\
(0.083)\end{array}$ & & \\
\hline $\mathrm{T} \times$ Altruism & & & & & & & $\begin{array}{l}-0.086 \\
(0.114)\end{array}$ & $\begin{array}{c}0.123 \\
(0.096)\end{array}$ \\
\hline Altruism & & & & & & & $\begin{array}{c}-0.206^{* *} \\
(0.081)\end{array}$ & $\begin{array}{c}-0.293^{* * *} \\
(0.072)\end{array}$ \\
\hline Constant & $\begin{array}{l}-0.130 \\
(0.121)\end{array}$ & $\begin{array}{c}-0.181 \\
(0.124)\end{array}$ & $\begin{array}{l}0.337^{* *} \\
(0.134)\end{array}$ & $\begin{array}{c}0.108 \\
(0.139)\end{array}$ & $\begin{array}{c}0.279^{* *} \\
(0.140)\end{array}$ & $\begin{array}{c}0.059 \\
(0.142)\end{array}$ & $\begin{array}{c}0.027 \\
(0.139)\end{array}$ & $\begin{array}{c}-0.019 \\
(0.134)\end{array}$ \\
\hline Admin. cont. & Yes & Yes & Yes & Yes & Yes & Yes & Yes & Yes \\
\hline Survey cont. & No & Yes & No & Yes & No & Yes & No & Yes \\
\hline Obs & 685 & 677 & 685 & 677 & 685 & 677 & 683 & 674 \\
\hline
\end{tabular}

Notes: OLS regressions. Robust standard errors in parentheses. ${ }^{* * *}-p<0.01,{ }^{* *}-p<0.05,{ }^{*}-p<0.1$. Admin. controls consists of data from administrative records and includes age, civil status, number of children, urban/rural home, education, total taxable income in 2010, wage income in 2009, net wealth in 2006 as well as total UI benefits and welfare transfers in 2009. Survey controls consists of variables gathered from our first survey, pre-treatment, and includes bias, media habits, party preference, beliefs about the role of luck and taxation in the economy as well as moral attitudes toward redistribution. Redist-Moral is a summary measure of the variables Just and Care. Just is a binary indicator for expressing that one supports redistribution because it leads to a more just society. Care is a binary indicator for expressing that one supports redistribution because one cares about the welfare of others. Outcome Index is a summary measure of right-of-center political preferences. See detailed definition in Section 2. 
TABle A.16: Heterogeneous efFects By Prior VAlues With CONTrols 2

\begin{tabular}{|c|c|c|c|c|c|c|c|c|}
\hline & \multicolumn{8}{|c|}{ Dependent variable: Low Demand for Redistribution } \\
\hline & (1) & $(2)$ & $(3)$ & (4) & $(5)$ & (6) & (7) & (8) \\
\hline Treated & $\begin{array}{c}0.050 \\
(0.034)\end{array}$ & $\begin{array}{c}0.053 \\
(0.033)\end{array}$ & $\begin{array}{l}0.106^{*} \\
(0.060)\end{array}$ & $\begin{array}{l}0.104^{*} \\
(0.060)\end{array}$ & $\begin{array}{l}0.120^{*} \\
(0.064)\end{array}$ & $\begin{array}{l}0.128^{* *} \\
(0.063)\end{array}$ & $\begin{array}{l}0.094^{*} \\
(0.050)\end{array}$ & $\begin{array}{c}0.063 \\
(0.048)\end{array}$ \\
\hline $\mathrm{T} \times$ Redist-Moral & $\begin{array}{l}-0.047 \\
(0.038)\end{array}$ & $\begin{array}{l}-0.048 \\
(0.038)\end{array}$ & & & & & & \\
\hline Redist-Moral & $\begin{array}{c}-0.188^{* * * *} \\
(0.028)\end{array}$ & $\begin{array}{c}-0.144^{* * *} \\
(0.030)\end{array}$ & & & & & & \\
\hline $\mathrm{T} \times$ Just & & & $\begin{array}{l}-0.080 \\
(0.073)\end{array}$ & $\begin{array}{c}-0.074 \\
(0.073)\end{array}$ & & & & \\
\hline Just & & & $\begin{array}{c}-0.334^{* * *} \\
(0.053)\end{array}$ & $\begin{array}{c}-0.254^{* * *} \\
(0.056)\end{array}$ & & & & \\
\hline $\mathrm{T} \times$ Care & & & & & $\begin{array}{c}-0.100 \\
(0.076)\end{array}$ & $\begin{array}{c}-0.106 \\
(0.075)\end{array}$ & & \\
\hline Care & & & & & $\begin{array}{c}-0.297^{* * *} \\
(0.056)\end{array}$ & $\begin{array}{c}-0.210^{* * *} \\
(0.058)\end{array}$ & & \\
\hline $\mathrm{T} \times$ Altruism & & & & & & & $\begin{array}{l}-0.039 \\
(0.073)\end{array}$ & $\begin{array}{c}0.036 \\
(0.071)\end{array}$ \\
\hline Altruism & & & & & & & $\begin{array}{c}-0.126^{* *} \\
(0.052)\end{array}$ & $\begin{array}{r}-0.158^{* * *} \\
(0.051)\end{array}$ \\
\hline Constant & $\begin{array}{c}0.362^{* * *} \\
(0.080)\end{array}$ & $\begin{array}{c}0.394^{* * *} \\
(0.093)\end{array}$ & $\begin{array}{c}0.600^{* * *} \\
(0.086)\end{array}$ & $\begin{array}{c}0.569^{* * *} \\
(0.101)\end{array}$ & $\begin{array}{c}0.557^{* * *} \\
(0.091)\end{array}$ & $\begin{array}{c}0.531^{* * *} \\
(0.104)\end{array}$ & $\begin{array}{c}0.452^{* * * *} \\
(0.089)\end{array}$ & $\begin{array}{c}0.483^{* * *} \\
(0.100)\end{array}$ \\
\hline Admin. cont. & Yes & Yes & Yes & Yes & Yes & Yes & Yes & Yes \\
\hline Survey cont. & No & Yes & No & Yes & No & Yes & No & Yes \\
\hline Obs & 685 & 677 & 685 & 677 & 685 & 677 & 683 & 674 \\
\hline
\end{tabular}

Notes: OLS regressions. Robust standard errors in parentheses. ${ }^{* * *}-p<0.01,{ }^{* *}-p<0.05,{ }^{*}-p<0.1$. Admin. controls consists of data from administrative records and includes age, civil status, number of children, urban/rural home, education, total taxable income in 2010, wage income in 2009, net wealth in 2006 as well as total UI benefits and welfare transfers in 2009. Survey controls consists of variables gathered from our first survey, pre-treatment, and includes bias, media habits, party preference, beliefs about the role of luck and taxation in the economy as well as moral attitudes toward redistribution. Redist-Moral is a summary measure of the variables Just and Care. Just is a binary indicator for expressing that one supports redistribution because it leads to a more just society. Care is a binary indicator for expressing that one supports redistribution because one cares about the welfare of others. Against-Redist is a dummy indicating below-median demand for redistribution. See detailed definition in Section 2. 
TABle A.17: Heterogeneous effects By PRior VAlues with CONTROls 3

\begin{tabular}{|c|c|c|c|c|c|c|c|c|}
\hline & \multicolumn{8}{|c|}{ Dependent variable: Support for the Conservative Party } \\
\hline & (1) & $(2)$ & $(3)$ & $(4)$ & $(5)$ & $(6)$ & $(7)$ & (8) \\
\hline Treated & $\begin{array}{c}0.040 \\
(0.035)\end{array}$ & $\begin{array}{c}0.058^{* *} \\
(0.029)\end{array}$ & $\begin{array}{c}0.009 \\
(0.072)\end{array}$ & $\begin{array}{c}0.045 \\
(0.062)\end{array}$ & $\begin{array}{c}-0.055 \\
(0.075)\end{array}$ & $\begin{array}{c}-0.002 \\
(0.061)\end{array}$ & $\begin{array}{c}0.084 \\
(0.052)\end{array}$ & $\begin{array}{c}0.029 \\
(0.038)\end{array}$ \\
\hline $\mathrm{T} \times$ Redist-Moral & $\begin{array}{l}0.059 \\
(0.043)\end{array}$ & $\begin{array}{l}0.033 \\
(0.035)\end{array}$ & & & & & & \\
\hline Redist-Moral & $\begin{array}{c}-0.215^{* * *} \\
(0.033)\end{array}$ & $\begin{array}{c}-0.084^{* * *} \\
(0.030)\end{array}$ & & & & & & \\
\hline $\mathrm{T} \times \mathrm{Just}$ & & & $\begin{array}{c}0.058 \\
(0.081)\end{array}$ & $\begin{array}{c}0.024 \\
(0.069)\end{array}$ & & & & \\
\hline Just & & & $\begin{array}{c}-0.351^{* * *} \\
(0.062)\end{array}$ & $\begin{array}{r}-0.122^{* *} \\
(0.059)\end{array}$ & & & & \\
\hline $\mathrm{T} \times$ Care & & & & & $\begin{array}{c}0.143^{*} \\
(0.084)\end{array}$ & $\begin{array}{c}0.089 \\
(0.069)\end{array}$ & & \\
\hline Care & & & & & $\begin{array}{c}-0.384^{* * *} \\
(0.065)\end{array}$ & $\begin{array}{c}-0.156^{* * *} \\
(0.059)\end{array}$ & & \\
\hline $\mathrm{T} \times$ Altruism & & & & & & & $\begin{array}{l}-0.043 \\
(0.073)\end{array}$ & $\begin{array}{c}0.085 \\
(0.059)\end{array}$ \\
\hline Altruism & & & & & & & $\begin{array}{l}-0.078 \\
(0.056)\end{array}$ & $\begin{array}{c}-0.120^{* *} \\
(0.047)\end{array}$ \\
\hline Constant & $\begin{array}{l}0.139^{*} \\
(0.083)\end{array}$ & $\begin{array}{l}-0.007 \\
(0.078)\end{array}$ & $\begin{array}{c}0.378^{* * *} \\
(0.099)\end{array}$ & $\begin{array}{c}0.072 \\
(0.092)\end{array}$ & $\begin{array}{c}0.397^{* * *} \\
(0.101)\end{array}$ & $\begin{array}{c}0.097 \\
(0.092)\end{array}$ & $\begin{array}{l}0.201^{* * *} \\
(0.093)\end{array}$ & $\begin{array}{c}0.062 \\
(0.084)\end{array}$ \\
\hline Admin. cont. & Yes & Yes & Yes & Yes & Yes & Yes & Yes & Yes \\
\hline Survey cont. & No & Yes & No & Yes & No & Yes & No & Yes \\
\hline Obs & 595 & 588 & 595 & 588 & 595 & 588 & 594 & 586 \\
\hline
\end{tabular}

Notes: OLS regressions. Robust standard errors in parentheses. ${ }^{* *}-p<0.01,{ }^{* *}-p<0.05,{ }^{*}-p<0.1$. Admin. controls consists of data from administrative records and includes age, civil status, number of children, urban/rural home, education, total taxable income in 2010, wage income in 2009, net wealth in 2006 as well as total UI benefits and welfare transfers in 2009. Survey controls consists of variables gathered from our first survey, pre-treatment, and includes bias, media habits, party preference, beliefs about the role of luck and taxation in the economy as well as moral attitudes toward redistribution. Redist-Moral is a summary measure of the variables Just and Care. Just is a binary indicator for expressing that one supports redistribution because it leads to a more just society. Care is a binary indicator for expressing that one supports redistribution because one cares about the welfare of others. Cons. Party is a dummy indicating support for the Conservative Party. See detailed definition in Section 2. 
TABle A.18: Heterogeneous EFFeCts By PRior VAlues with CONTROls 4

\begin{tabular}{|c|c|c|c|c|c|c|c|c|}
\hline & \multicolumn{8}{|c|}{ Dependent variable: Demand for Lower Taxes } \\
\hline & (1) & $(2)$ & (3) & (4) & $(5)$ & $(6)$ & $(7)$ & (8) \\
\hline Treated & $\begin{array}{c}0.023 \\
(0.036)\end{array}$ & $\begin{array}{c}0.040 \\
(0.035)\end{array}$ & $\begin{array}{c}0.062 \\
(0.064)\end{array}$ & $\begin{array}{c}0.063 \\
(0.060)\end{array}$ & $\begin{array}{c}0.046 \\
(0.068)\end{array}$ & $\begin{array}{c}0.055 \\
(0.065)\end{array}$ & $\begin{array}{c}0.054 \\
(0.051)\end{array}$ & $\begin{array}{c}0.029 \\
(0.049)\end{array}$ \\
\hline $\mathrm{T} \times$ Redist-Moral & $\begin{array}{l}-0.020 \\
(0.041)\end{array}$ & $\begin{array}{l}-0.011 \\
(0.039)\end{array}$ & & & & & & \\
\hline Redist-Moral & $\begin{array}{c}-0.166^{* * *} \\
(0.030)\end{array}$ & $\begin{array}{c}-0.122^{* * *} \\
(0.031)\end{array}$ & & & & & & \\
\hline $\mathrm{T} \times \mathrm{Just}$ & & & $\begin{array}{c}-0.056 \\
(0.078)\end{array}$ & $\begin{array}{l}-0.033 \\
(0.075)\end{array}$ & & & & \\
\hline Just & & & $\begin{array}{c}-0.300^{* * *} \\
(0.056)\end{array}$ & $\begin{array}{c}-0.224^{* * *} \\
(0.058)\end{array}$ & & & & \\
\hline $\mathrm{T} \times$ Care & & & & & $\begin{array}{c}-0.031 \\
(0.081)\end{array}$ & $\begin{array}{c}-0.019 \\
(0.078)\end{array}$ & & \\
\hline Care & & & & & $\begin{array}{c}-0.256^{* * *} \\
(0.059)\end{array}$ & $\begin{array}{c}-0.171^{* * *} \\
(0.060)\end{array}$ & & \\
\hline $\mathrm{T} \times$ Altruism & & & & & & & $\begin{array}{l}-0.032 \\
(0.077)\end{array}$ & $\begin{array}{c}0.061 \\
(0.073)\end{array}$ \\
\hline Altruism & & & & & & & $\begin{array}{l}-0.094^{*} \\
(0.057)\end{array}$ & $\begin{array}{c}-0.142^{* * *} \\
(0.053)\end{array}$ \\
\hline Constant & $\begin{array}{c}0.372^{* * *} \\
(0.086)\end{array}$ & $\begin{array}{c}0.388^{* * *} \\
(0.100)\end{array}$ & $\begin{array}{c}0.583^{* * *} \\
(0.094)\end{array}$ & $\begin{array}{c}0.541^{* * *} \\
(0.108)\end{array}$ & $\begin{array}{c}0.544^{* * *} \\
(0.097)\end{array}$ & $\begin{array}{c}0.501^{* * *} \\
(0.110)\end{array}$ & $\begin{array}{c}0.444^{* * *} \\
(0.093)\end{array}$ & $\begin{array}{c}0.471^{* * *} \\
(0.105)\end{array}$ \\
\hline Admin. cont. & Yes & Yes & Yes & Yes & Yes & Yes & Yes & Yes \\
\hline Survey cont. & No & Yes & No & Yes & No & Yes & No & Yes \\
\hline Obs & 678 & 670 & 678 & 670 & 678 & 670 & 676 & 667 \\
\hline
\end{tabular}

Notes: OLS regressions. Robust standard errors in parentheses. ${ }^{* * *}-p<0.01,{ }^{* *}-p<0.05,{ }^{*}-p<0.1$. Admin. controls consists of data from administrative records and includes age, civil status, number of children, urban/rural home, education, total taxable income in 2010, wage income in 2009, net wealth in 2006 as well as total UI benefits and welfare transfers in 2009. Survey controls consists of variables gathered from our first survey, pre-treatment, and includes bias, media habits, party preference, beliefs about the role of luck and taxation in the economy as well as moral attitudes toward redistribution. Redist-Moral is a summary measure of the variables Just and Care. Just is a binary indicator for expressing that one supports redistribution because it leads to a more just society. Care is a binary indicator for expressing that one supports redistribution because one cares about the welfare of others. Decrease Tax is a dummy indicating a desire to lower income taxes. See detailed definition in Section 2. 